\title{
Near-axis subsidence rates, hydrothermal circulation, and thermal structure of mid-ocean ridge crests
}

\author{
James R. Cochran and W. Roger Buck \\ Lamont-Doherty Earth Observatory of Columbia University, Palisades, New York, USA
}

\begin{abstract}
We systematically investigated near-axis subsidence on the ridge flanks of intermediate and fast spreading mid-ocean ridges using bathymetric data from well-surveyed portions of the Southeast Indian Ridge (spreading at $72-76 \mathrm{~mm} / \mathrm{yr}$ ), the northern East Pacific Rise (91-96 mm/yr), and the southern East Pacific Rise $(144 \mathrm{~mm} / \mathrm{yr})$. In all three regions, the mean subsidence rate of young ( $<1-1.4 \mathrm{Ma}$ ) seafloor is less than $220 \mathrm{~m} / \mathrm{m} . \mathrm{y} .{ }^{1 / 2}$. The distribution of individual estimates shows a distinct peak at $180-220 \mathrm{~m} / \mathrm{m} . \mathrm{y} \cdot{ }^{1 / 2}$ with few profiles having subsidence rates greater than $275 \mathrm{~m} / \mathrm{m} . \mathrm{y}^{1 / 2}{ }^{1 / 2}$ The observed subsidence rates are significantly lower than both the worldwide average $\left(\sim 350 \mathrm{~m} / \mathrm{m} . \mathrm{y} .{ }^{1 / 2}\right)$ and subsidence rates observed for older lithosphere at the same ridge segments. Intense hydrothermal circulation at the ridge axis can result in low subsidence rates on the adjacent ridge flanks provided the vigorous flow is confined to the immediate vicinity $(<\sim 5$ $\mathrm{km}$ ) of the axis. According to our model, the extremely vigorous hydrothermal circulation ceases off-axis, and conductive heat flow becomes a primary mechanism of vertical heat transport on the ridge flanks. The very low geothermal gradient within the cooled portion of the uppermost lithosphere retards conductive cooling, and the cooled area needs to be heated from below before a geothermal gradient can be established which permits significant heat to be conducted out of the lithosphere. As a result, subsidence in very young ( 0.1 -1 Ma) lithosphere is suppressed. A simple one-dimensional thermal model with a Nusselt number parameterization was used to estimate the effect of hydrothermal circulation. An upper layer with a high Nusselt number and the half-space that it overlies are initially at a temperature of $1300^{\circ} \mathrm{C}$ and the surface is maintained at $0^{\circ} \mathrm{C}$. After $0.1 \mathrm{~m}$.y. of cooling (about 3.5 to $7 \mathrm{~km}$ from the spreading axis), the Nusselt number of the top layer is set to 1 so that normal conduction is simulated in the cooled layer. We used an explicit finite difference method to solve for the temporal changes in temperature with depth. This model produces subsidence rates in the range that we observe for $N u$ in the range of 15-30. Isotherms resulting from the modeling imply rapid lithospheric thickening very near the axis, which is incompatible with most current models for the formation of the bathymetric axial high observed at fast spreading mid-ocean ridges.
\end{abstract}

\section{Introduction}

An early corollary of plate tectonics was that both the depth of the ocean floor and oceanic heat flow are primarily controlled by conductive cooling of the lithosphere as it is transported away from a mid-ocean ridge. As a result, the average seafloor depth is expected to increase and heat flow decrease monotonically with lithospheric age [Langseth et al., 1966; McKenzie, 1967; Sclater and Francheteau, 1970].

A systematic empirical relationship between depth and age was developed by Sclater et al. [1971]. The general characteristics of the observed depth-age curve can be explained by a simple thermal model for the evolution of the ocean floor. As the new crust moves away from the ridge axis, it cools by conduction and is incorporated in a cold thermal boundary layer or lithosphere. Continued cooling results in thermal contraction and thickening of the lithosphere. If no additional heat is supplied to the lithosphere, then this "half-space" or "thermal boundary layer" model predicts that the depth of the seafloor below the ridge axis depth is proportional to the square root of its age [Parker and Olden-

Copyright 2001 by the American Geophysical Union.

Paper number 2001JB000379.

$0148-0227 / 01 / 2001 \mathrm{JB} 000379 \$ 09.00$ burg, 1973; Davis and Lister, 1974]. This is the relationship between depth and age generally observed for seafloor less than about 70 m.y. old.

Parsons and Sclater [1977] compiled bathymetric data from a number of ridges and found the best fitting square root of age relationship for young lithosphere $(<\sim 60 \mathrm{Ma})$ to be $d(t)=2500+$ $350 t^{1 / 2} \mathrm{~m}$ in both the Atlantic and Pacific ( $t$ denotes lithospheric age in millions of years). They used their results to quantitatively solve for a number of lithospheric parameters including asthenospheric temperature and the coefficient of thermal expansion. Although there has been ongoing discussion of appropriate parameters [e.g., Sandwell and Schubert, 1982; Cazenave et al., 1983; Johnson and Carlson, 1992; Stein and Stein, 1992, 1994; Stein et al., 1995] and of mechanisms of supplying heat to the base of the lithosphere [e.g., Parsons and McKenzie, 1978; Heestand and Crough, 1981; Doin and Fleitout, 1996], the square root of age relationship between depth and lithospheric age, resulting from conductive cooling of the lithosphere, has remained an essential part of the plate tectonics paradigm for over 20 years.

The thermal models for crustal depth also predict a systematic decrease in heat flow with age [McKenzie, 1967; Sleep, 1969; Sclater and Francheteau, 1970]. Heat flow data, however, show considerably greater scatter when plotted as a function of crustal age than do depths. In particular, heat flow measurements from 


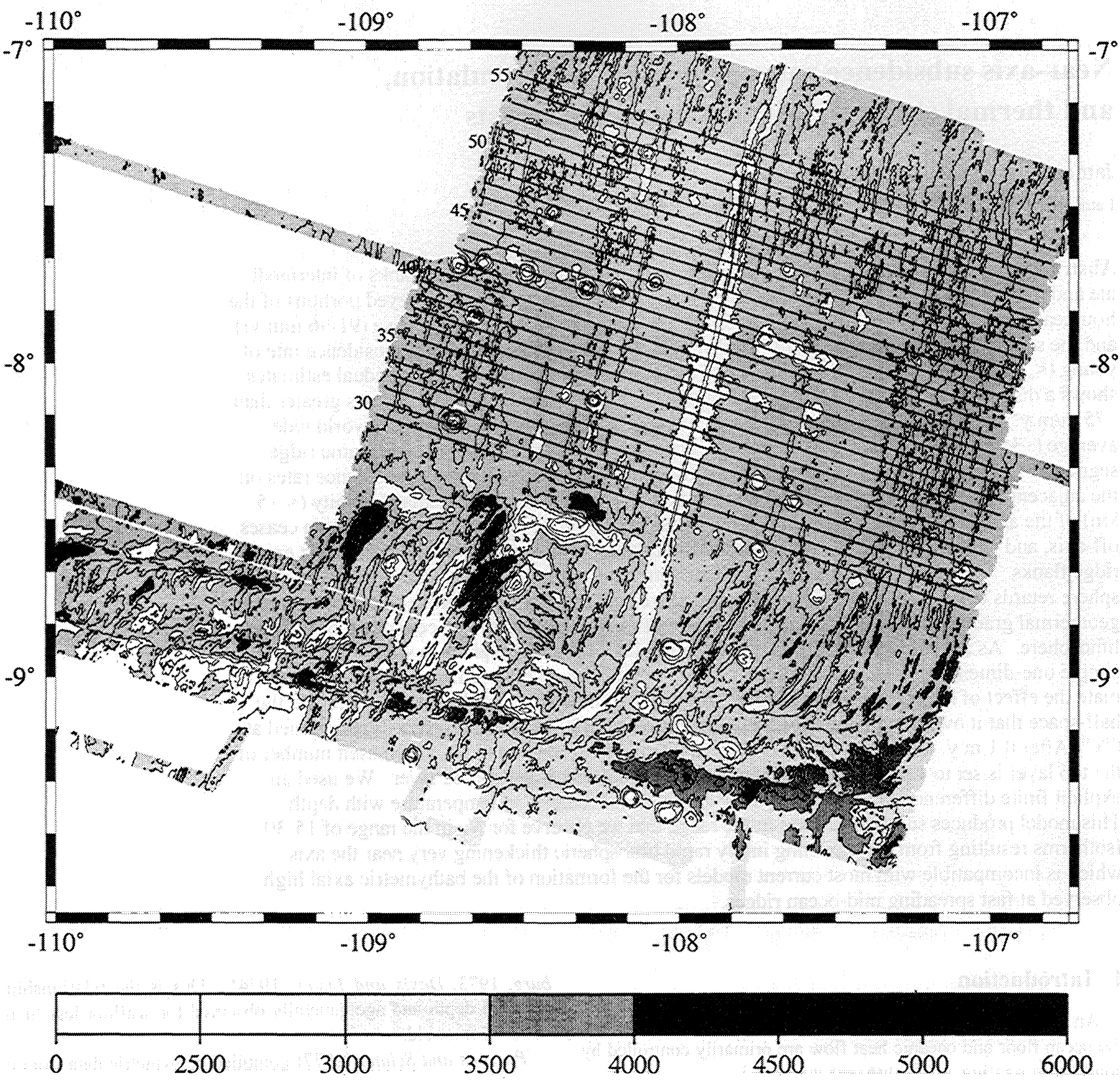

Figure 1. Hydrosweep swath bathymetry map of the southern East Pacific Rise from $7^{\circ} \mathrm{S}$ to $9^{\circ} 15^{\prime} \mathrm{S}$ to the north of the Wilkes transform. Contour interval is $250 \mathrm{~m}$, and shading changes at $500-\mathrm{m}$ intervals. Solid lines show the location of profiles shown in Figure 2. Profile numbers to the left of the ship tracks correspond to those in Figure 2. Profiles are at approximately 6-km intervals. The region extending $50 \mathrm{~km}$ north of the transform has been disturbed by a series of short-lived propagating rifts [Goff et al., 1993] and was not considered in this study. The total spreading rate is $144 \mathrm{~mm} / \mathrm{yr}$ [DeMets et al., 1990].

young oceanic crust show the greatest scatter and were found to be significantly lower than predicted by the thermal models [e.g., Talwani et al., 1971; Lister, 1972; Anderson and Hobart, 1976]. The low heat flow recorded for young seafloor is widely accepted to result from hydrothermal circulation which removes heat from the upper crust, lowering the local geothermal gradient and inhibiting conductive heat flow [Sclater et al., 1974; Anderson and Hobart, 1976; Williams et al., 1986; Stein and Stein, 1994; Stein et al., 1995].

Hydrothermal circulation at mid-ocean ridge crests is a major geologic process with profound effects on the chemistry of the upper crust [e.g., Wolery and Sleep, 1976; Seyfried, 1987; Von
Damm, 1995], formation of mineral deposits [Rona, 1980, 1988], the chemistry of the oceans [e.g., Wolery and Sleep, 1976; Edmond et al., 1979; Hart and Staudigal, 1982; Lilley et al., 1995] and the development and nurture of biological communities [e.g., Grassle, 1986; Lutz and Kennish, 1993; Lutz et al., 1994]. In addition to significant chemical and biological effects, hydrothermal circulation near mid-ocean ridge axes is also an important and efficient mechanism in transferring heat out of the upper portion of the lithosphere. Stein and Stein [1994] used the "heat flow discrepancy" (difference between observed heat flow and that predicted from thermal models of the cooling lithosphere in which all cooling is by conduction) to estimate that $3.2 \times 10^{12} \mathrm{~W}$ 
or about $10 \%$ of the global oceanic heat flux occurs very near the axis in crust less than $1 \mathrm{~m} . \mathrm{y}$. old.

The removal of such a large quantity of heat in a narrow region centered at the ridge crest must greatly affect the temperature structure within the crust in the vicinity of ridge axes. Since depth depends on the thermal structure, we expect that hydrothermal modification of the temperature will have an effect on depth and subsidence rates near the ridge axis. The purpose of this study is to systematically investigate subsidence rates of young lithosphere at fast and intermediate spreading ridges in order to determine the effect that removal of such a large amount of heat near the axis has on the depth and subsidence of the immediately adjacent ridge flank. The result of this study is that subsidence rates in young lithosphere $(<1 .-1.4 \mathrm{Ma})$ are consistently found to be about half of the long-term rate at the same section of the ridge. We will explore this observation using a simple one-dimensional thermal model to investigate the implications for lateral extent of extremely vigorous hydrothermal circulation, the near-axis thermal structure, the variation in lithospheric thickness, and the creation of axial morphology.

\section{Observations of Near-Axis Subsidence Rates}

There has been a great emphasis during the past 15 years on mapping the mid-ocean ridge system. These studies initially concentrated on the axis, but more recently have extended onto the flanks in selected areas. As a result, there are now several portions of the mid-ocean ridge system with complete bathymetric coverage extending to $1 \mathrm{Ma}$ or more onto the ridge flanks and along the axis for at least an entire segment. We will analyze data from three such portions of the mid-ocean ridge system with differing spreading rates. These are the intermediate spreading Southeast Indian Ridge (SEIR) between $90^{\circ} \mathrm{E}$ and $110^{\circ} \mathrm{E}(72-76$ $\mathrm{mm} / \mathrm{yr}$ ), the fast spreading northern East Pacific Rise (NEPR) near $13^{\circ} \mathrm{N}(91-96 \mathrm{~mm} / \mathrm{yr})$, and the extremely fast spreading southern East Pacific Rise (SEPR) near $8^{\circ} \mathrm{S}$ (144 mm/yr).

\subsection{Southern East Pacific Rise}

Cochran et al. [1993] surveyed a 250-km-long portion of the extremely fast spreading ( $144 \mathrm{~mm} / \mathrm{yr}$ ) southern East Pacific Rise from $7^{\circ} \mathrm{S}$ to $9^{\circ} 30^{\prime} \mathrm{S}$, immediately to the north of the Wilkes transform. The survey obtained complete swath bathymetry coverage to about $100 \mathrm{~km}(\sim 1.4 \mathrm{Ma})$ from the axis on both flanks (Figure 1). The spreading rate of $144 \mathrm{~mm} / \mathrm{yr}$ used in this study was determined using the NUVEL-1 [DeMets et al., 1990] PacificNazca pole. The area is within a few degrees of the magnetic equator with the result that the north-south trending ridge axis does not generate intelligible seafloor spreading magnetic anomalies. Farther south on the EPR, where seafloor spreading anomalies can be recognized, NUVEL-1 rates agree well with the observed spreading rates [DeMets et al., 1990]

The $125-\mathrm{km}$-long Wilkes transform is the second fastest slipping oceanic transform, exceeded only by the Garrett, located $575 \mathrm{~km}$ to the south, which is slipping at $\sim 150 \mathrm{~mm} / \mathrm{yr}$. The Wilkes transform is not completely stable and rifts have periodically propagated northward out of the transform, forming a series of short-lived "nannoplates" [Goff et al., 1993]. As a result, the seafloor for about $50 \mathrm{~km}$ to the north of the transform is tectonically disturbed (Figure 1).

In this study, we will concentrate on the stable northern portion of the survey. In particular, we will examine subsidence rates within a $160-\mathrm{km}$-long segment extending from a $1.2-\mathrm{km}$ offset overlapping spreading center (OSC) at $8^{\circ} 38^{\prime} \mathrm{N}$ to an $8-\mathrm{km}$ offset OSC at $7^{\circ} 12^{\prime} \mathrm{N}$. Wang and Cochran [1993] concluded that the $7^{\circ} 12^{\prime} \mathrm{N}-8^{\circ} 38^{\prime} \mathrm{S}$ segment has been in existence as a stable tectonic unit with relatively stationary boundaries since at least $1 \mathrm{Ma}$ based on morphologic evidence. This evidence includes a series of fossil overlap basins and abandoned ridge tips on the ridge flanks along a flow line through the $7^{\circ} 12^{\prime} \mathrm{N}$ OSC, and changes in the abyssal hill fabric marking the trace of the small $8^{\circ} 38^{\prime} \mathrm{S}$ OSC (Figure 1).

The swath bathymetry data in Figure 1 were collected along lines run nearly perpendicular to the axis with a spacing of $\sim 6$ $\mathrm{km}$. We projected the Hydrosweep center beam data from each line perpendicular to the axis to form a series of evenly spaced bathymetric profiles across the ridge crest. The location of the track lines used is shown in Figure 1. The profiles are shown in Figure 2, and are numbered following Wang and Cochran [1993]. The latitude at which each profile crosses the ridge axis is also noted.

A stacked profile is also shown in Figure 2. The $7^{\circ} 12^{\prime} \mathrm{S}-$ $8^{\circ} 38^{\prime} \mathrm{S}$ segment is magmatically vigorous [Macdonald et al., 1989] with a significant number of seamounts present on the ridge flanks [Cochran et al., 1993]. As a result, both flanks of profiles 42 and 43 and the western flank of profiles 52 and 53 were too disturbed by seamounts to use and were excluded from the stacked profile. In addition, individual seamounts were removed from 12 other profiles prior to stacking, leaving a gap of less than $10 \mathrm{~km}$ in those profiles.

We fit a square root of age curve to each flank of the stacked profile. The bathymetry within $10 \mathrm{~km}$ from the axis was excluded to avoid including the axial high in the calculation. The axial high at fast spreading ridges is widely considered either to be buoyantly supported by a low-density region in the upper mantle beneath the axis [Madsen et al., 1984; Wilson, 1992; Wang and Cochran, 1993], or to result from stresses within the lithosphere [Eberle and Forsyth, 1998; Buck et al.; 1998]. The best fitting subsidence rates are $179.8 \mathrm{~m} / \mathrm{m}$.y. ${ }^{1 / 2}$ for the west flank and $170.8 \mathrm{~m} / \mathrm{m} . \mathrm{y} .{ }^{1 / 2}$ for the east flank (Table 1). These best fitting subsidence curves are superimposed on each of the observed bathymetric profiles in Figure 2.

We also fit square root of age curves to bathymetric data from 10 to $100 \mathrm{~km}$ from the axis for all of the individual center beam profiles in the $7^{\circ} 12^{\prime}-8^{\circ} 38^{\prime} \mathrm{S}$ segment. Each line was again divided into eastern flank and western flank profiles, which were fit separately, and data within $10 \mathrm{~km}$ from the axis were excluded. The mean subsidence rate determined from the individual profiles is $170 \mathrm{~m} / \mathrm{m} . y .{ }^{1 / 2}$ (Table 1 ). If the two flanks are considered separately, the results are $167 \mathrm{~m} / \mathrm{m} . \mathrm{y} .^{1 / 2}$ for the west flank and $174 \mathrm{~m} / \mathrm{m} . \mathrm{y} .{ }^{1 / 2}$ for the east flank. A histogram showing the distribution of the individual determinations used is shown in Figure 3. The standard deviation of the mean for these 48 samples is $\pm 11.7 \mathrm{~m} / \mathrm{m} . \mathrm{y}^{1 / 2}$, so the $95 \%$ confidence interval for the mean subsidence within the segment is $147.1-192.9 \mathrm{~m} / \mathrm{m} . \mathrm{y} .^{1 / 2}$ and the $99 \%$ confidence interval is $139.8-200.2 \mathrm{~m} / \mathrm{m} . \mathrm{y} .^{1 / 2}$. The probability that the actual mean subsidence rate is as great as 250 $\mathrm{m} / \mathrm{m} . \mathrm{y}^{1 / 2}$ is $<10^{-9}$.

Cochran [1986] found subsidence rates of 323-330 m/m.y. ${ }^{1 / 2}$ for $0-1 \mathrm{~m}$.y. crust for the same portion of the EPR using a few older profiles. However, he included the 400-m axial high in the calculation, which has the effect of artificially steepening the gradient over the short 1-m.y. distance. If the axial high is not removed from the stacked profile prior to fitting, then best fitting subsidence rates of $372.2 \mathrm{~m} / \mathrm{m} . \mathrm{y}^{1 / 2}$ and $359.8 \mathrm{~m} / \mathrm{m} . \mathrm{y}^{1 / 2}$ are found for the west and east flanks, respectively. However, as shown in 

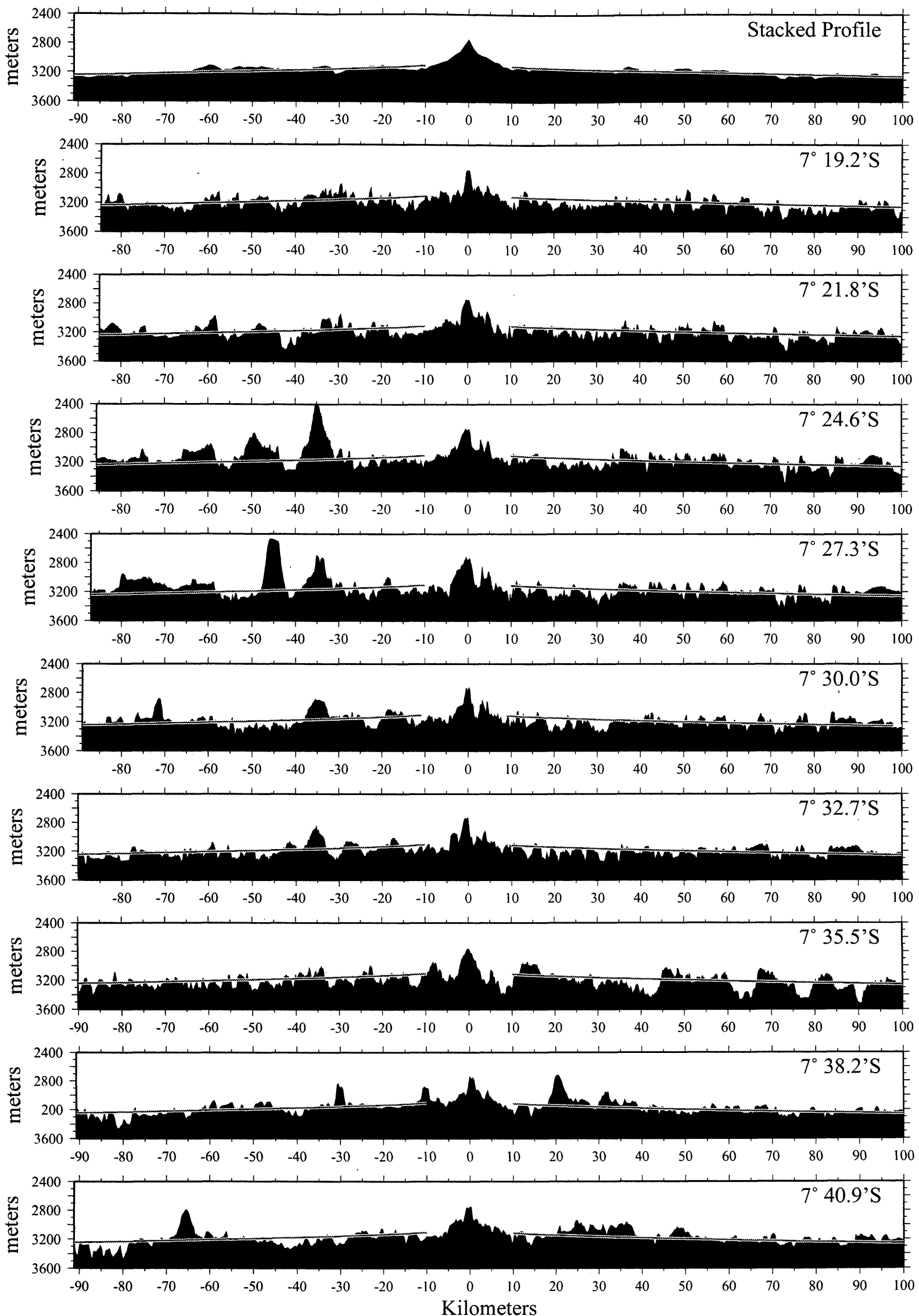

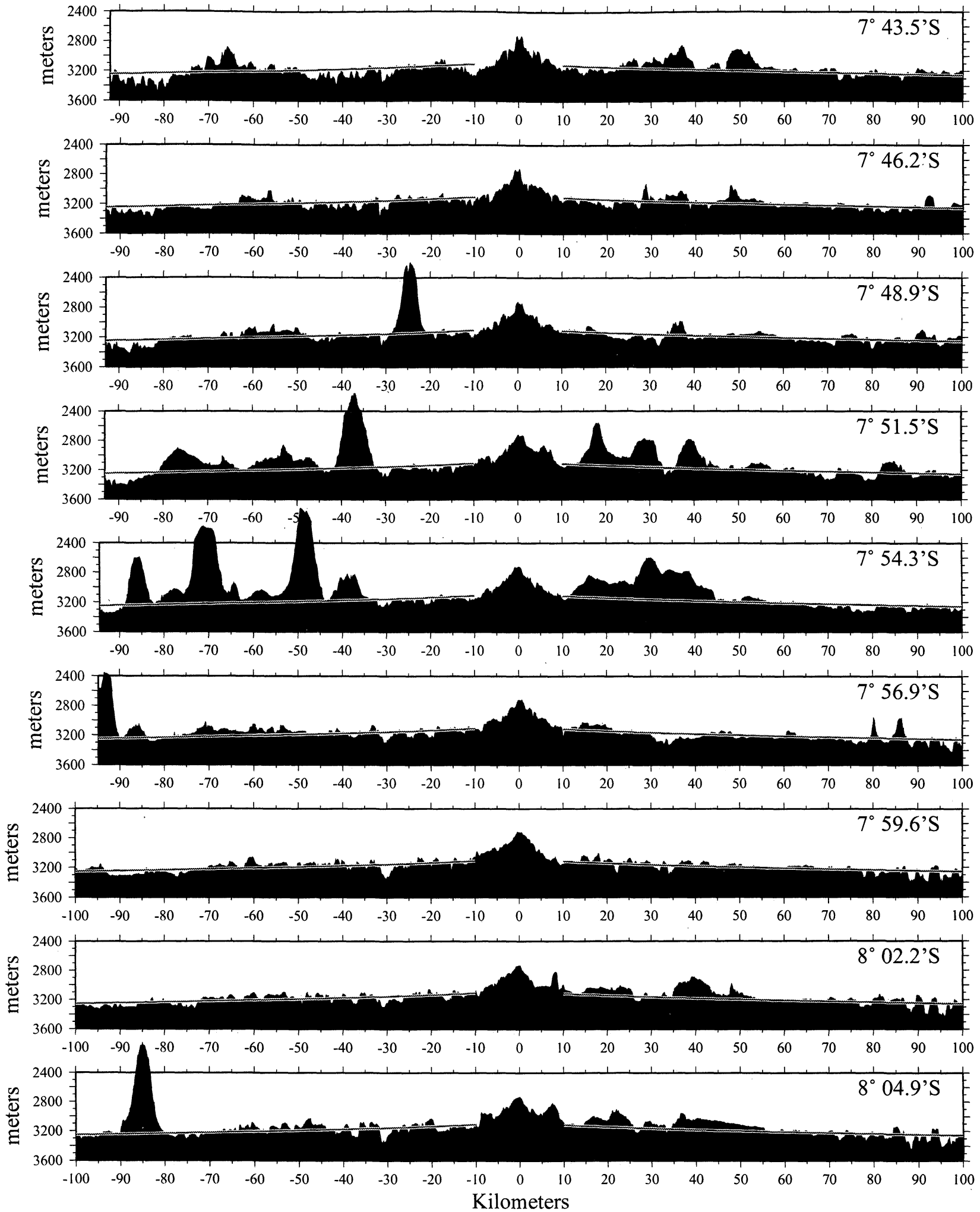

Figure 2. (continued)

Figure 2. (opposite) Bathymetric profiles across the axis of the southern East Pacific Rise in the $7^{\circ} 12^{\prime} \mathrm{S}-8^{\circ} 38^{\prime} \mathrm{S}$ segment. All profiles are projected parallel to the local spreading direction. The western flank is to the left. The latitude at which each profile crosses the ridge axis is noted, and the profiles are numbered following Wang and Cochran [1993]. Location of the profiles is shown in Figure 1. A stacked profile is also shown. The square root of age subsidence curve which best fits the stacked profile is superimposed on each profile. The best fitting subsidence rates are $179.8 \mathrm{~m} / \mathrm{m} . \mathrm{y} .{ }^{1 / 2}$ for the west flank and $170.8 \mathrm{~m} / \mathrm{m} . \mathrm{y} .{ }^{1 / 2}$ for the east flank. Large seamounts precluded use of the western flank of profiles 52 and 53 and both flanks of profiles 42 and 43 in construction of the stacked profile and analysis of subsidence rates. 

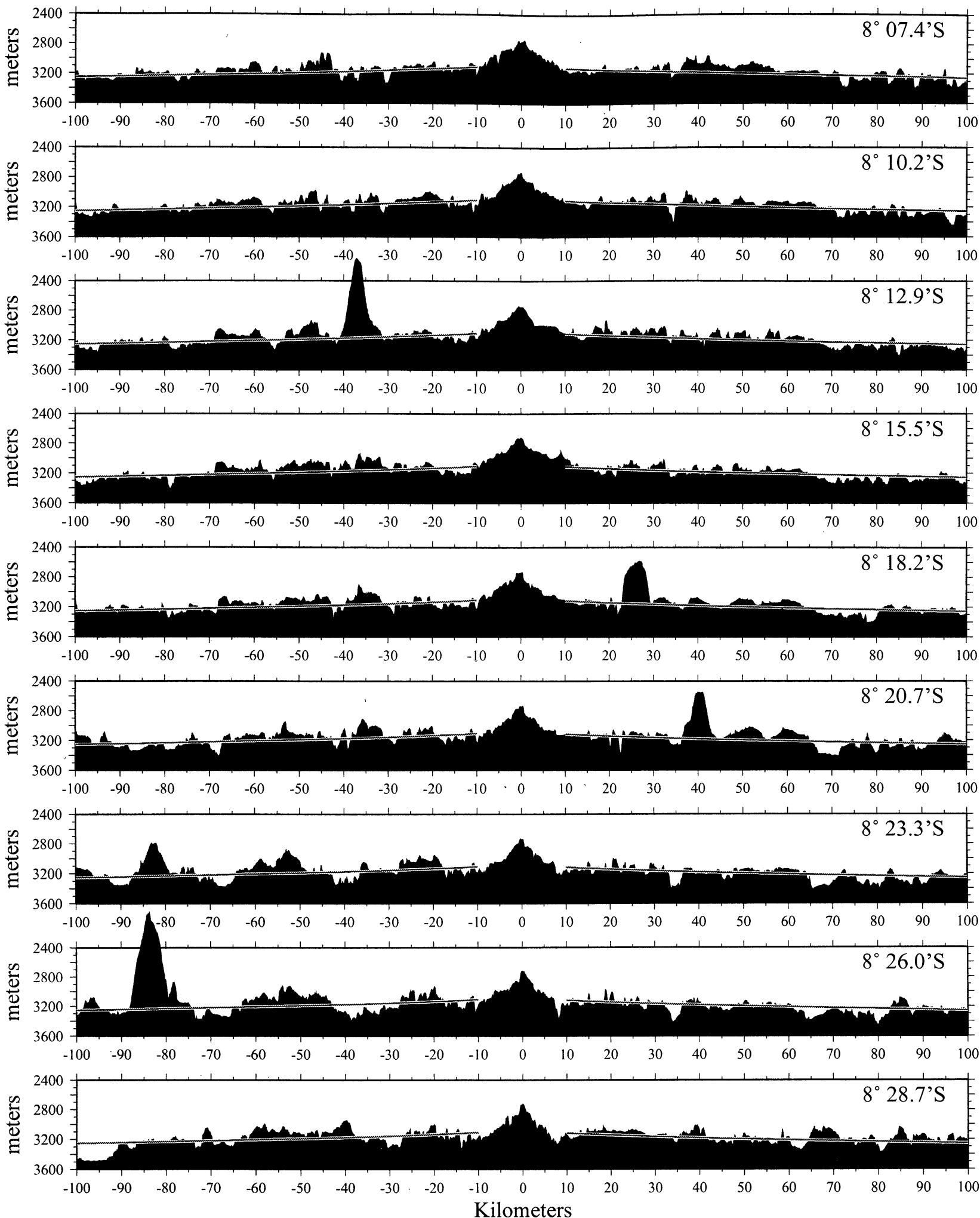

Figure 2. (continued)

Figure 4, the axial high deviates greatly from the linear square root of age curve followed by the ridge flanks, and as a result, the best fitting subsidence curves determined including the axial high do not provide a good visual fit to the data (Figure 4).

Cochran [1986] also found that the longer-term subsidence rate to $5 \mathrm{Ma}$ on the eastern flank of this portion of the EPR is 398 $\mathrm{m} / \mathrm{m} . \mathrm{y} .^{1 / 2}$. On the western flank, bathymetric data between the Yaquina (at $6.2^{\circ} \mathrm{S}$ ) and Wilkes fracture zones extended to 2.4-Ma crust and gave a subsidence rate of $259 \mathrm{~m} / \mathrm{m} . \mathrm{y} .{ }^{1 / 2}$ [Cochran, 1986]. The asymmetric subsidence is a characteristic feature of the southern EPR which has been related to the presence of the "South Pacific Superswell" to the west of the ridge axis [e.g., 
Table 1. Near-axis Subsidence Rates

\begin{tabular}{|c|c|c|c|c|c|c|}
\hline \multirow[t]{2}{*}{ Ridge } & \multirow[t]{2}{*}{ Segment } & \multirow[t]{2}{*}{ Flank } & \multirow[t]{2}{*}{ Profiles } & \multicolumn{2}{|c|}{$\begin{array}{l}\text { Subsidence Rate, } \\
\mathrm{m} / \mathrm{m} . \mathrm{y} .\end{array}$} & \multirow[t]{2}{*}{$\begin{array}{c}\text { Standard Deviation } \\
\text { of the Mean }\end{array}$} \\
\hline & & & & Stacked & Profile Mean & \\
\hline $\begin{array}{l}\text { Southern } \\
\text { East Pacific }\end{array}$ & $7^{\circ} 12^{\prime}-8^{\circ} 38^{\prime} \mathrm{S}$ & $\begin{array}{l}\text { both } \\
\text { west } \\
\text { east }\end{array}$ & $\begin{array}{l}48 \\
22 \\
26\end{array}$ & $\begin{array}{l}179.8 \\
170.8\end{array}$ & $\begin{array}{l}170 \\
167 \\
174\end{array}$ & $\begin{array}{l}11.7 \\
13.6 \\
18.7\end{array}$ \\
\hline $\begin{array}{l}\text { Northern } \\
\text { East Pacific }\end{array}$ & $12^{\circ} 54^{\prime}-14^{\circ} 30^{\prime} \mathrm{N}$ & $\begin{array}{l}\text { west } \\
\text { east }\end{array}$ & $\begin{array}{l}26 \\
21\end{array}$ & $\begin{array}{c}225.7 \\
43.7\end{array}$ & $\begin{array}{c}221 \\
48\end{array}$ & $\begin{array}{l}12.7 \\
23.3\end{array}$ \\
\hline \multirow[t]{6}{*}{ Southeast Indian } & all & both & 84 & & 161 & 13.2 \\
\hline & M3 & $\begin{array}{l}\text { north } \\
\text { south }\end{array}$ & $\begin{array}{l}12 \\
11\end{array}$ & $\begin{array}{l}126.9 \\
259.0\end{array}$ & $\begin{array}{l}119 \\
230\end{array}$ & $\begin{array}{l}30.6 \\
48.4\end{array}$ \\
\hline & P1 & $\begin{array}{l}\text { north } \\
\text { south }\end{array}$ & $\begin{array}{l}9 \\
8\end{array}$ & $\begin{array}{l}157.9 \\
164.8\end{array}$ & $\begin{array}{l}165 \\
226\end{array}$ & $\begin{array}{l}50.0 \\
17.0\end{array}$ \\
\hline & P2 & $\begin{array}{l}\text { north } \\
\text { south }\end{array}$ & $\begin{array}{l}8 \\
8\end{array}$ & $\begin{array}{l}118.9 \\
154.6\end{array}$ & $\begin{array}{l}133 \\
144\end{array}$ & $\begin{array}{l}33.7 \\
18.0\end{array}$ \\
\hline & $\mathrm{R}$ & $\begin{array}{l}\text { north } \\
\text { south }\end{array}$ & $\begin{array}{l}7 \\
9\end{array}$ & $\begin{array}{c}78.3 \\
188.7\end{array}$ & $\begin{array}{l}124 \\
212\end{array}$ & $\begin{array}{l}32.7 \\
47.5\end{array}$ \\
\hline & S1 & $\begin{array}{l}\text { north } \\
\text { south }\end{array}$ & $\begin{array}{l}6 \\
6\end{array}$ & $\begin{array}{c}130.8 \\
90.3\end{array}$ & $\begin{array}{l}139 \\
80\end{array}$ & $\begin{array}{l}44.6 \\
57.4\end{array}$ \\
\hline
\end{tabular}

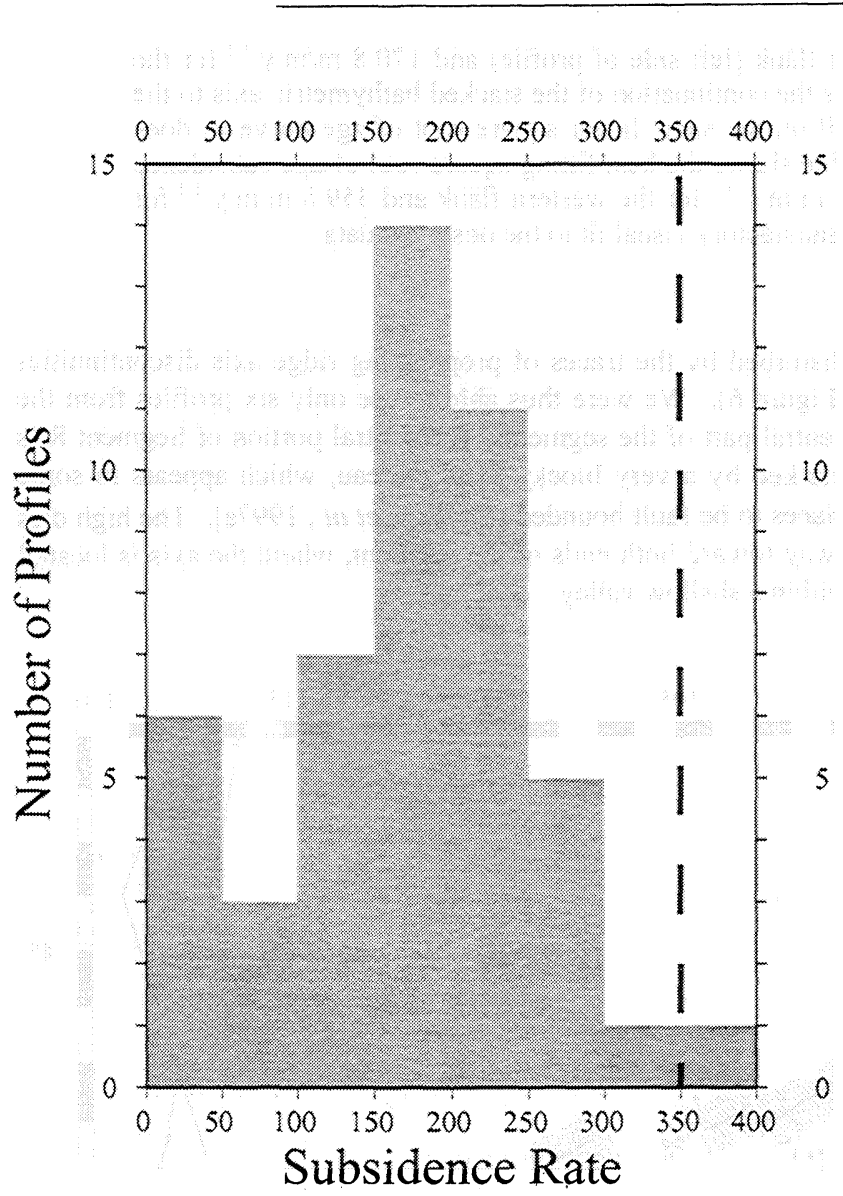

Figure 3. Histogram showing the distribution of subsidence rates determined from the profiles in Figure 2. Subsidence rate estimates were obtained for each flank of the profiles using data $>10 \mathrm{~km}$ from the ridge axis. The heavy dashed line shows the average global long-term ridge flank subsidence rate of 350 $\mathrm{m} / \mathrm{m} . \mathrm{y} .{ }^{1 / 2}$ [Parsons and Sclater, 1977]. The mean of these samples is $170 \mathrm{~m} / \mathrm{m} . \mathrm{y} .^{1 / 2}$ and the $99 \%$ confidence interval for the mean subsidence rate is $139.8-200.2 \mathrm{~m} / \mathrm{m} . \mathrm{y} .{ }^{1 / 2}$.
McNutt and Fischer, 1987]. Both eastern and western flank longer-term subsidence rates are significantly greater than the near-axis rates.

\subsection{Southeast Indian Ridge}

Cochran et al. [1997a] and Sempere et al. [1997] reported on a geophysical survey of a $2300-\mathrm{km}$-long section of the intermediate spreading rate $\left(72-76 \mathrm{~mm} / \mathrm{yr}\right.$ total rate) SEIR between $88^{\circ} \mathrm{E}$ and $118^{\circ} \mathrm{E}$. The survey included complete swath bathymetry coverage of eight second-order ridge segments extending a total of $1100 \mathrm{~km}$ along the axis to a distance of $\sim 45 \mathrm{~km}(\sim 1.2 \mathrm{Ma})$ from the axis on each flank (Figure 5). The average line spacing was about $9 \mathrm{~km}$. We will analyze data from five of the eight segments (M3, P1, P2, R, and S1). The ridge flanks of segments P3 and $\mathrm{S} 4$ are highly disturbed by propagating rift tracks [Cochran et al., 1997b, 1998], while segment T is characterized by a deep $(>1000 \mathrm{~m})$ axial rift valley and large-amplitude abyssal hill relief which makes accurate determination of the subsidence rate difficult.

Spreading rates and azimuths used in our analysis were calculated using the NUVEL-1 Australian-Antarctic pole [DeMets et al., 1990]. The spreading rates calculated from this pole are consistent to $\sim 1 \mathrm{~mm} / \mathrm{yr}$ with mean spreading rates determined from unpublished magnetics data collected along with the bathymetry data shown in Figures $6-11$.

Figure 6 shows bathymetric maps of the five segments with the location of profiles used shown by fine lines. Projected bathymetric profiles are shown in Figures 7 - 11. A stacked profile is also shown for each segment. Profiles disturbed by seamounts, which we did not include in the analysis, are noted in the captions to Figures $7-11$. The segments display a wide range of axial morphology. Segment P1 has a well-developed "EPR-like" axial high in the center of the segment, which becomes lower and rifted toward segment ends. Segment M3 also has a broad axial high for a short region near the center of the segment, but it is not as well developed as at P1. Segments 


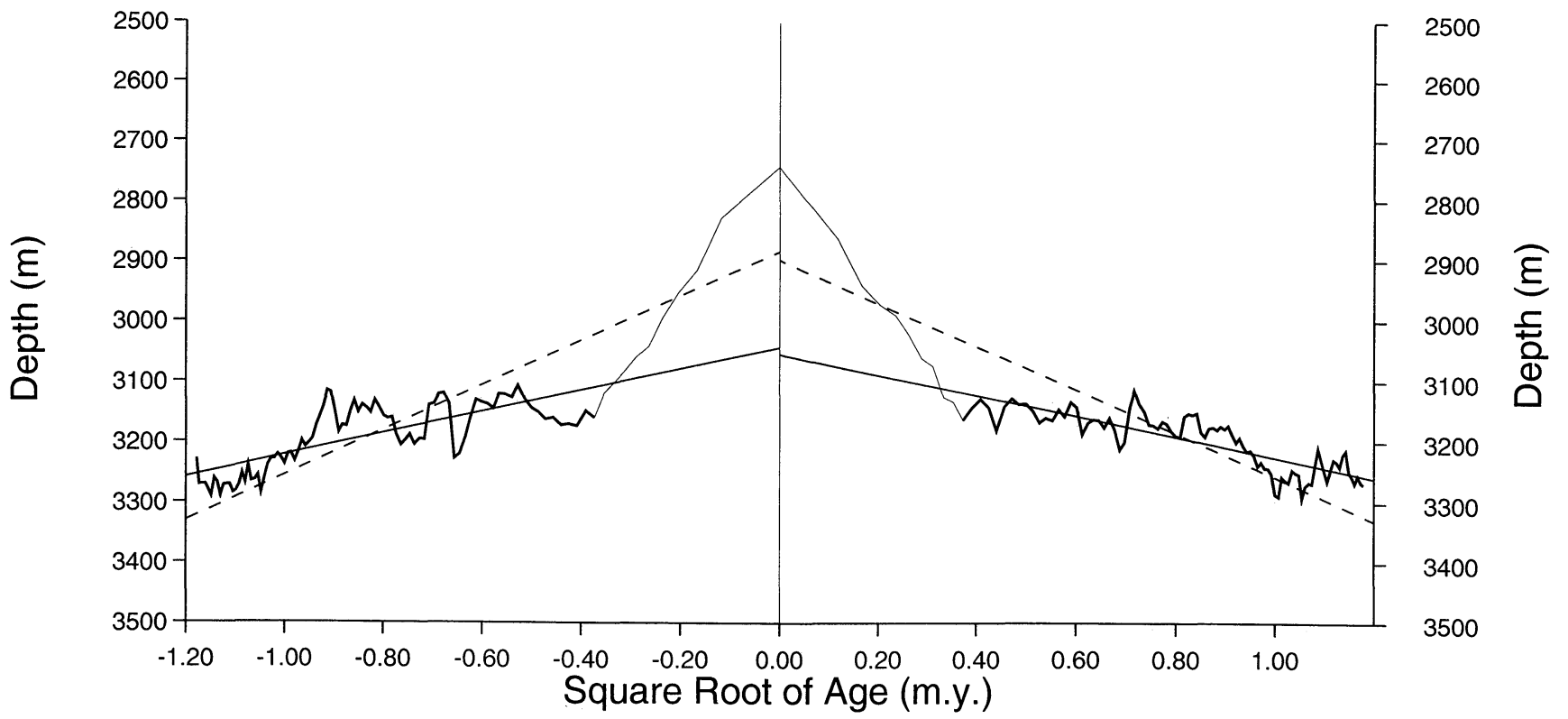

Figure 4. Stacked bathymetry profile from the $7^{\circ} 12^{\prime} \mathrm{S}-8^{\circ} 38^{\prime} \mathrm{S}$ segment and best fitting square root of age subsidence curves plotted as a function of square root of age. The heavy solid line shows the portions of the stacked profile at distances greater than $10 \mathrm{~km}$ from the axis. The medium thickness solid line shows the best fitting square root of age subsidence curves to the stacked profile at distances greater than $10 \mathrm{~km}$ from the axis. The slopes of these subsidence curves are $179.8 \mathrm{~m} / \mathrm{m} . \mathrm{y} .{ }^{1 / 2}$ for the western flank (left side of profile) and $170.8 \mathrm{~m} / \mathrm{m} . \mathrm{y} .{ }^{1 / 2}$ for the eastern flank (right side of profile). The fine solid line shows the continuation of the stacked bathymetric axis to the axis. The bathymetry of the axial high clearly does not fall on the same linear square root of age curve as does bathymetry from 10 to $100 \mathrm{~km}$ from the axis. The dashed line shows the best fitting square root of age subsidence curve for data from the axis to $100 \mathrm{~km}$ with slopes of $372.2 \mathrm{~m} / \mathrm{m} . \mathrm{y} .{ }^{1 / 2}$ for the western flank and $359.8 \mathrm{~m} / \mathrm{m} . \mathrm{y} .{ }^{1 / 2}$ for the eastern flank. These subsidence curves do not provide a satisfactory visual fit to the observed data.

P2 and S1 have typically nondescript intermediate-rate axial morphology. Segment P2 is characterized by a low, rifted axial high, while $\mathrm{S} 1$ has a shallow axial rift valley, which deepens near the segment boundaries. The combination of backscatter amplitude and the presence of a small axial magnetic high were very useful in precisely locating the axis on some profiles in these segments. The ridge flanks at both ends of Segment S1 are disturbed by the traces of propagating ridge axis discontinuities (Figure 6). We were thus able to use only six profiles from the central part of the segment. The central portion of Segment $\mathrm{R}$ is marked by a very blocky axial plateau, which appears in some places to be fault bounded [Cochran et al., 1997a]. The high dies away toward both ends of the segment, where the axis is located within a shallow valley.

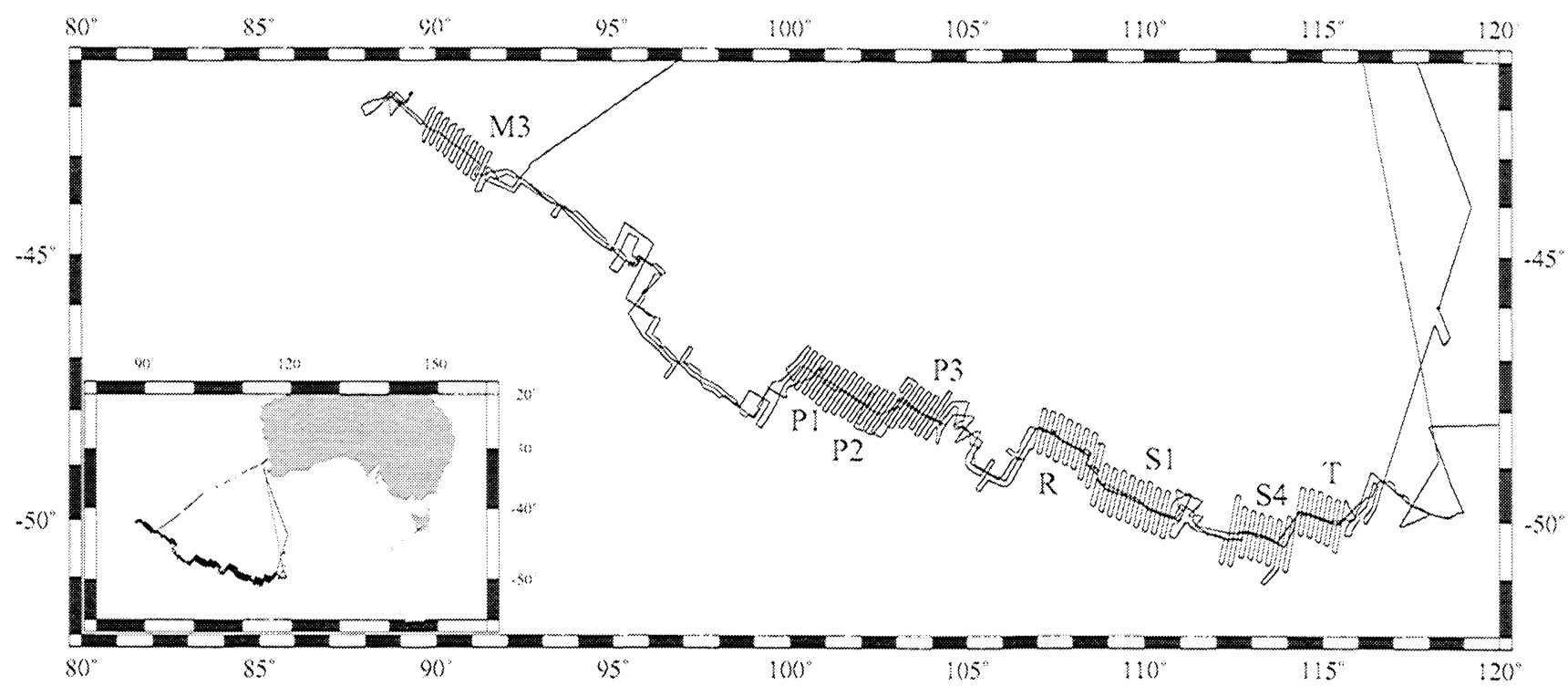

Figure 5. Track chart showing the location of bathymetric data from the Southeast Indian Ridge used in this study. Bathymetry maps of the individual segments studied are given in Figure 6, and center beam bathymetric profiles are shown in Figures 7-11. Segments are labeled following Cochran et al. [1997a]. 


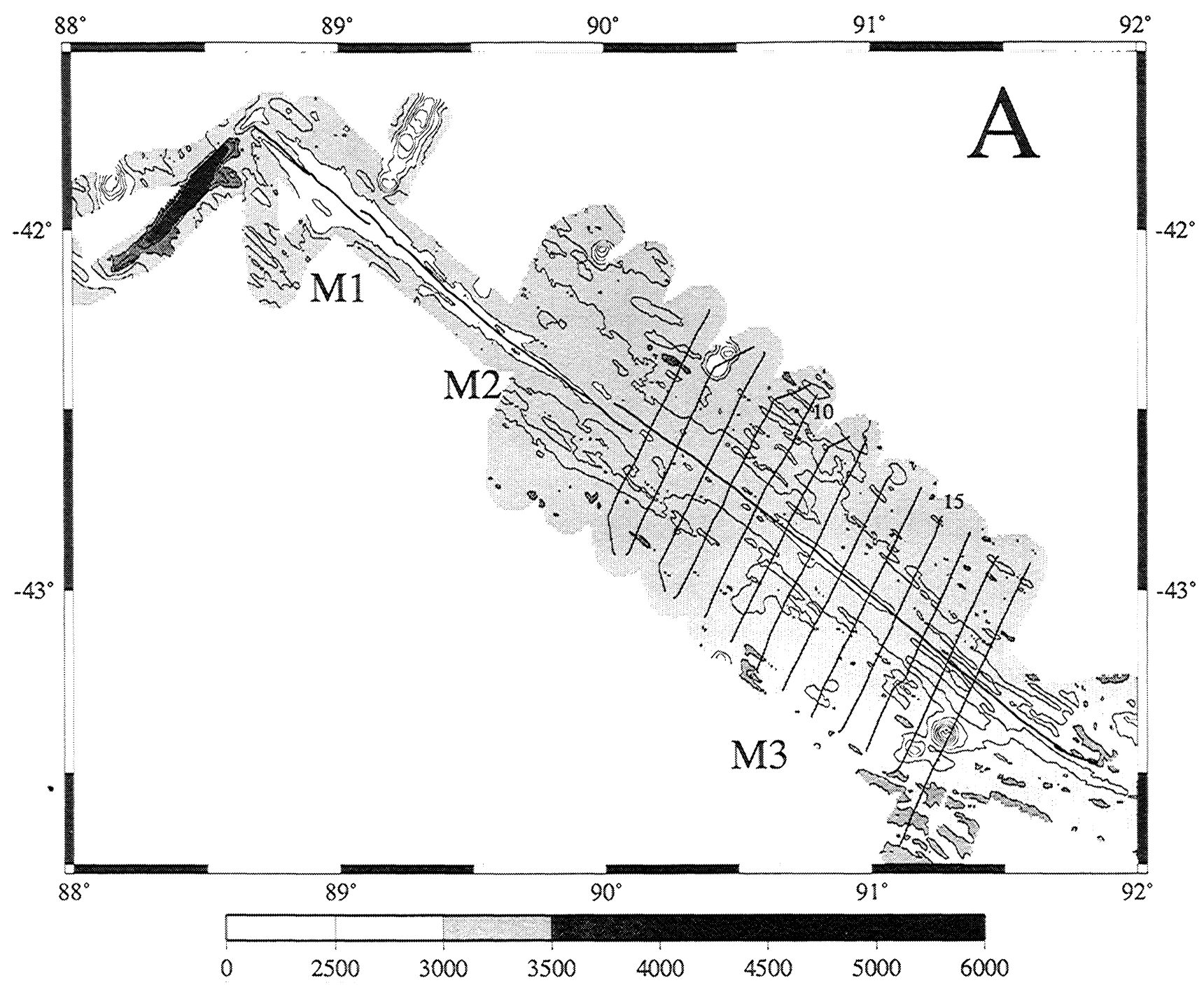

Figure 6a. SeaBeam swath bathymetry map of Segments M1-M3 on the Southeast Indian Ridge. Contour interval is $250 \mathrm{~m}$, and shading changes at $500-\mathrm{m}$ intervals. The ridge axis is shown by a solid line. The location of the segment is shown in Figure 5. Solid lines across the axis show the location of profiles shown in Figure 7. Profile numbers correspond to those in Figure 7. The total spreading rate is $72 \mathrm{~mm} / \mathrm{yr}$.

Square root of age curves were fit to the portions of the stacked profiles more than $10 \mathrm{~km}$ from the axis on each flank for each segment. The results are tabulated in Table 1 and the best fitting subsidence curve for the segment is superimposed on the observed profiles in Figures 7 - 11. The best fitting subsidence rates vary from $78.3 \mathrm{~m} / \mathrm{m} . y .{ }^{1 / 2}$ for the north flank of Segment $R$ to $259.0 \mathrm{~m} / \mathrm{m} . \mathrm{y} .{ }^{1 / 2}$ for the south flank of Segment M3. With the exception of the south flank of Segment M3, all of the subsidence rate estimates are less than $188.7 \mathrm{~m} / \mathrm{m} . \mathrm{y} .{ }^{1 / 2}$, and eight of the ten are less than $165 \mathrm{~m} / \mathrm{m} . \mathrm{y}^{1 / 2}$. The best fitting subsidence curves for each segment are superimposed on the individual profiles in Figures 7 - 11 .

We also fit square root of age subsidence curves to each of the individual profiles shown in Figures $7-11$. The mean subsidence rate and standard deviation of the mean for each segment are tabulated in Table 1. The segment mean subsidence rates are very similar to the rates determined from the stacked profiles, as was the case for the southern EPR. The segment standard deviations of the mean are considerably larger than for the $7^{\circ} 12^{\prime} \mathrm{S}$ $8^{\circ} 38^{\prime}$ 'S southern EPR segment. The larger standard deviations of the mean are due in large part to the fact that the estimate of the mean subsidence is based on many fewer samples, as well as the shorter profile length and rougher abyssal hill morphology at the SEIR, which result in greater uncertainty in fitting the square root of age curves.

A histogram of individual determinations of the subsidence rate for the entire SEIR data set is shown in Figure 12. If we assume that the SEIR subsidence rate estimates are all drawn from a common population, then the distribution of samples shown in Figure 12 results in an estimated mean subsidence rate of $161 \mathrm{~m} / \mathrm{m} . \mathrm{y} .^{1 / 2}$. with a standard deviation of the mean of \pm 13.2 m.m.y. ${ }^{1 / 2}$. The $95 \%$ confidence interval for the mean subsidence rate is $135.1-186.9 \mathrm{~m} / \mathrm{m} . y .^{1 / 2}$ and the $99 \%$ confidence interval is $126.9-195.1 \mathrm{~m} / \mathrm{m} . \mathrm{y} .^{1 / 2}$. As with the SEIR data, the probability that the actual mean of the population from which the samples shown in Figures $7-11$ are drawn is as high as $250 \mathrm{~m} / \mathrm{m} . \mathrm{y}^{1 / 2}$ is less than $10^{-9}$.

Cochran [1986] utilized bathymetric profiles extending to $12-$ Ma crust on the SEIR and concluded (p. 442) that "the region west of the discordance appears to be subsiding symmetrically with a subsidence constant of $340-350 \mathrm{~m} / \mathrm{m} . \mathrm{y} .{ }^{1 / 2}$ ". The profiles used by Cochran [1986] are dominated by the region from 3 to 


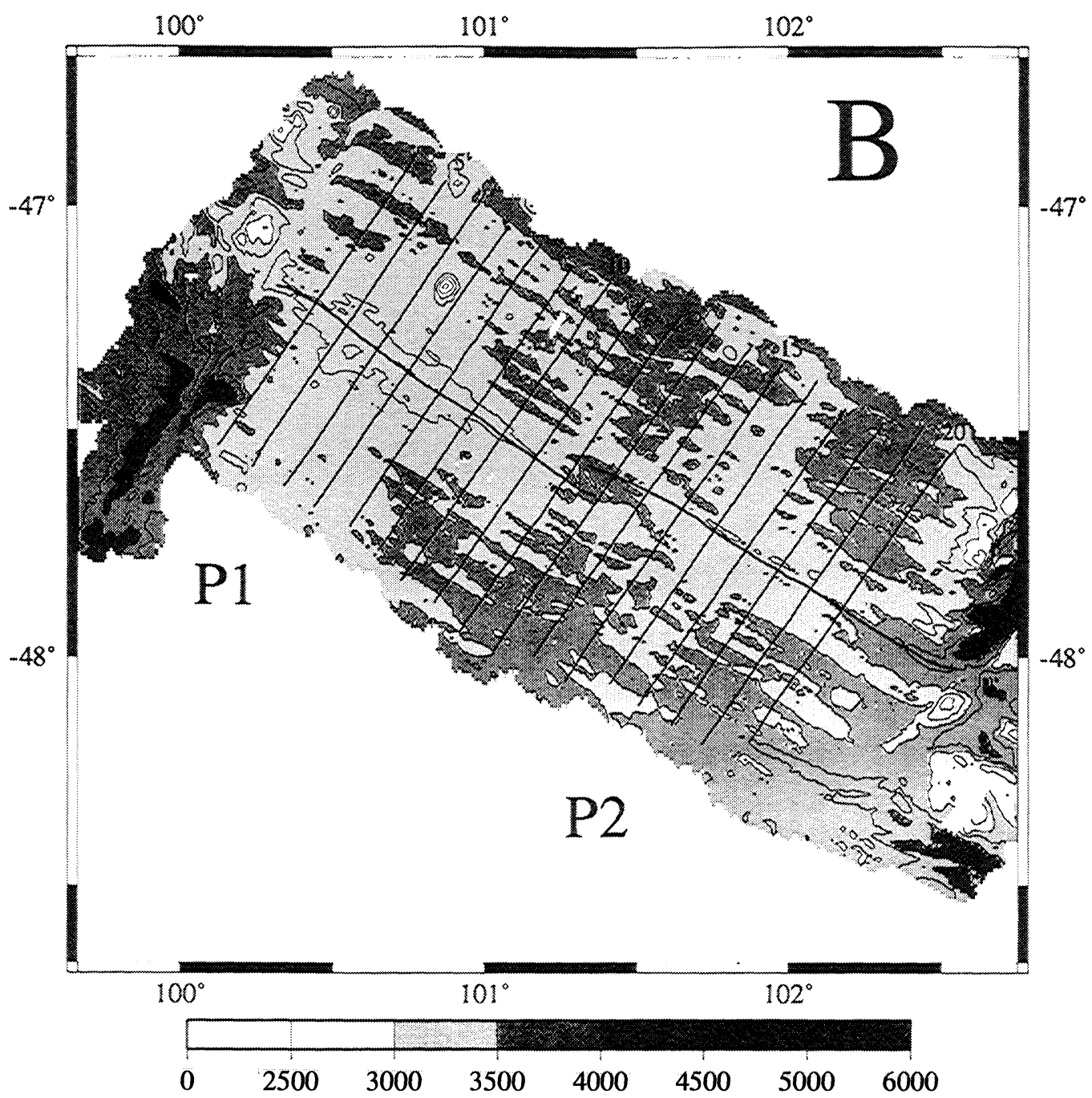

Figure 6b. SeaBeam swath bathymetry map of Segments P1 and P2 on the Southeast Indian Ridge. Contour interval is $250 \mathrm{~m}$, and shading changes at $500-\mathrm{m}$ intervals. The ridge axis is shown by a solid line. The location of the segment is shown in Figure 5. Solid lines across the axis show the location of profiles shown in Figures 8 and 9. Profile numbers correspond to those in Figures 8 and 9. The total spreading rate is $76 \mathrm{~mm} / \mathrm{yr}$.

12 Ma. Hayes and Kane [1994] also obtained long-term subsidence rates in the range of $\sim 280-350 \mathrm{~m} / \mathrm{m} . \mathrm{y} .^{1 / 2}$ for profiles in this portion of the SEIR. As at the very fast spreading SEPR, our observations at the intermediate-rate SEIR suggest the presence of low subsidence rates near the ridge crest which increase to the global average in older lithosphere.

\subsection{Northern East Pacific Rise}

The third region considered here is the fast spreading northern East Pacific Rise. We do not have bathymetric data available to us from a single systematic survey such as we utilized for the SEPR and SEIR studies. As a result, profiles were extracted from gridded bathymetric data [Macdonald et al., 1992]. The grid used has a grid interval of $300 \mathrm{~m}$. We digitized the axis at intervals of $3^{\prime}$ of latitude $(5.56 \mathrm{~km})$ on bathymetric maps and constructed profiles through each ridge axis location extending for $80 \mathrm{~km}$ onto each flank by sampling the bathymetric grids at 1 $\mathrm{km}$ intervals along the flow lines. Spreading rates and azimuths were determined from the NUVEL-1 Pacific-Cocos pole [DeMets et al., 1990]
The portion of the ridge chosen to investigate extends from a small $1.6-\mathrm{km}$ offset $\mathrm{OSC}$ at $12^{\circ} 54^{\prime} \mathrm{N}$ [Antrim et al., 1988] to $14^{\circ} 12^{\prime} \mathrm{N}$, about $30 \mathrm{~km}$ south of a $5-\mathrm{km}$ oblique second-order offset at $14^{\circ} 30^{\prime} \mathrm{N}$ [Macdonald et al., 1992] (Figure 13). The $12^{\circ} 54^{\prime} \mathrm{N}$ OSC, rather than the much larger $11^{\circ} 45^{\prime} \mathrm{N}$ OSC, was chosen as the southern limit because the bathymetric grid only extends about 20 to $55 \mathrm{~km}$ from the axis between $11^{\circ} 45^{\prime} \mathrm{N}$ and $12^{\circ} 54^{\prime} \mathrm{N}$. The northern limit of the study area was defined by the location where profiles began to be disturbed by the trace of the $14^{\circ} 30^{\prime} \mathrm{N}$ offset. This area was chosen rather than the much studied $9^{\circ} \mathrm{N}-10^{\circ} \mathrm{N}$ segment because profiles from the $9^{\circ} \mathrm{N}$ segment are disturbed by the trace of the $9^{\circ} 03^{\prime} \mathrm{N}$ OSC.

The profiles extracted from the gridded data are shown in Figure 14 along with a profile produced by stacking the extracted profiles. The axial morphology changes within the study area from a well-developed axial high in the south to a much lower, less prominent axial high in the north. Farther north, as it approaches the $14^{\circ} 30^{\prime} \mathrm{N}$ offset, the axis comes to be located within a shallow valley. A number of large seamounts are present on the eastern flank. Profiles eliminated from the analysis due to seamounts are noted in the caption to Figure 14. 


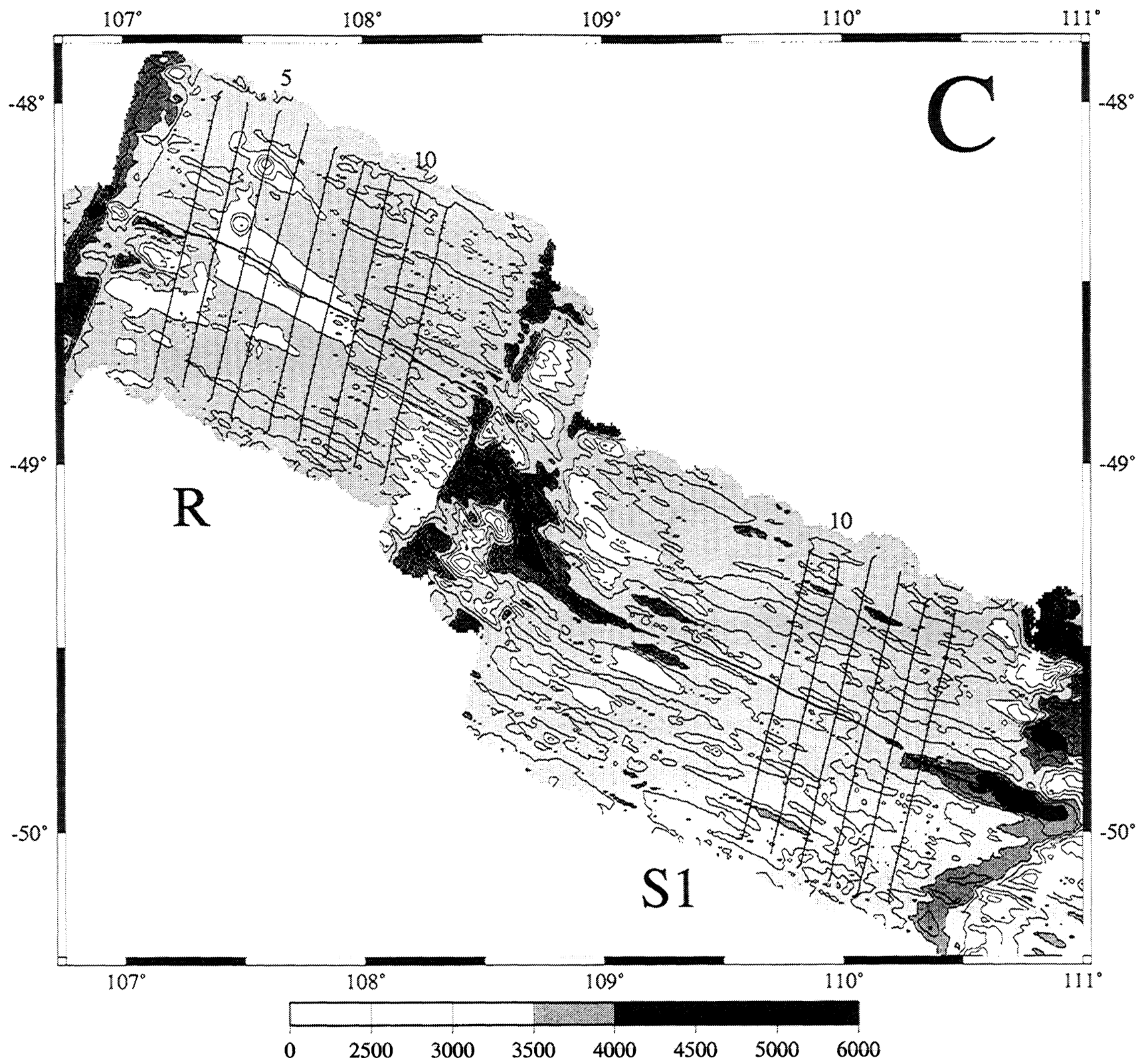

Figure 6c. SeaBeam swath bathymetry map of Segments R and S1 on the Southeast Indian Ridge, Contour interval is $250 \mathrm{~m}$, and shading changes at $500-\mathrm{m}$ intervals. The ridge axis is shown by a solid line. The location of the segment is shown in Figure 5. Solid lines across the axis show the location of profiles shown in Figures 10 and 11. Profile numbers correspond to those in Figures 10 and 11 . The total spreading rate is $76 \mathrm{~mm} / \mathrm{yr}$.

A square root of age curve was fit to each flank of the stacked profile for distances greater than $10 \mathrm{~km}$ from the axis on each flank. The best fitting subsidence rates are $225.7 \mathrm{~m} / \mathrm{m} . \mathrm{y} .^{1 / 2}$ for the western flank and $43.7 \mathrm{~m} / \mathrm{m} . \mathrm{y} .^{1 / 2}$ for the eastern flank. Subsidence curves with these rates are superimposed on the individual profiles in Figure 14. The great asymmetry across the axis and the very low subsidence rate on the eastern flank are both evident in the bathymetry map (Figure 13) and in the individual profiles.

Square root of age subsidence curves were also fit to each of the bathymetric profiles. The mean subsidence rates and standard deviations of the mean for each flank are tabulated in Table 1. Histograms showing the distribution of subsidence rate estimates for the eastern and western flanks are shown in Figure 15. The $95 \%$ confidence interval for the mean subsidence rate of the west flank is $196.1-245.9 \mathrm{~m} / \mathrm{m} . \mathrm{y} .{ }^{1 / 2}$. There is a $1.2 \%$ probability that the actual mean subsidence rate of the west flank is as great as $250 \mathrm{~m} / \mathrm{m} . \mathrm{y} .^{1 / 2}$ and less than $10^{-9}$ probability that it is greater than $300 \mathrm{~m} / \mathrm{m} . \mathrm{y} .{ }^{1 / 2}$.

The subsidence rate on the east flank is much lower. The mean observed subsidence rate is $48 \mathrm{~m} / \mathrm{m} . \mathrm{y} .{ }^{1 / 2}$ with the individual estimates spread fairly evenly between $-107 \mathrm{~m} / \mathrm{m} . y .{ }^{1 / 2}$ and 229 $\mathrm{m} / \mathrm{m} . \mathrm{y}^{1 / 2}$ (Fig. $15 \mathrm{~b}$ ). The $95 \%$ confidence limit for the mean subsidence on the eastern flank are $2.4-93.7 \mathrm{~m} / \mathrm{m} . \mathrm{y} .^{1 / 2}$. The reason for the great asymmetry in near-axis subsidence rates for this 

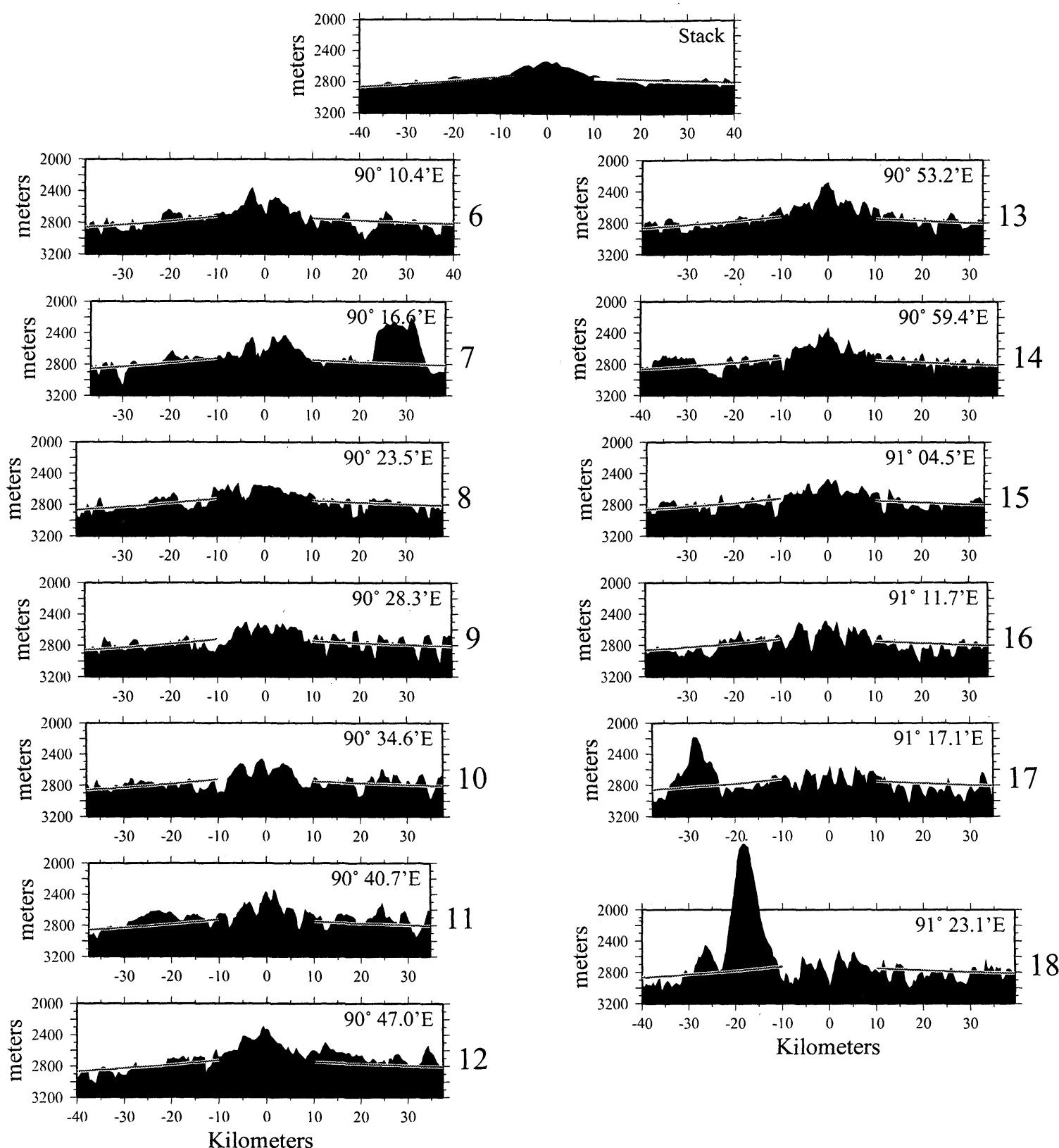

Figure 7. Bathymetric profiles across the axis from Segment M3 of the Southeast Indian Ridge. All profiles are projected parallel to the local spreading direction. The southern flank is to the left. The longitude at which each profile crosses the ridge axis is noted. Profile numbers correspond to those in Figure $6 \mathrm{a}$, which shows the location of the profiles. A stacked profile is also shown. The square root of age subsidence curve which best fits the stacked profile is superimposed on each profile. The best fitting subsidence rates are $126.9 \mathrm{~m} / \mathrm{m} . \mathrm{y}^{1 / 2}$ for the north flank and $259.0 \mathrm{~m} / \mathrm{m}$. y. $^{1 / 2}$ for the south flank. Large seamounts precluded use of the southern flank of profiles 17 and 18 and the northern flank of profile 7 in construction of the stacked profile and analysis of subsidence rates.

portion of the ridge axis is unclear and there is insufficient offaxis data available to determine to what distance off-axis the asymmetry persists.

\section{Hydrothermal Circulation and Near-Axis Subsidence Rates}

Estimates of subsidence rates from intermediate and fast spreading mid-ocean ridges with spreading rates varying over a wide range $(72 \mathrm{~mm} / \mathrm{yr}$ to $144 \mathrm{~mm} / \mathrm{yr}$ ) suggest that subsidence rates within about $1 \mathrm{Ma}$ of the axis are considerably less than those determined from older crust (Table 1). In general, the nearaxis subsidence rates, estimated from multiple profiles in each segment, are about half of both the Parsons and Sclater [1977] global average and of the long-term rate observed in the same region [Cochran, 1986].

In this section we will present a model based on the hypothesis that this observation can result from vigorous hydrothermal circulation in the immediate vicinity of the ridge axis. Since hydrothermal circulation is a very efficient mechanism to remove heat from the crust, it might be expected that it would result in faster, rather than slower, subsidence. However, we will show 

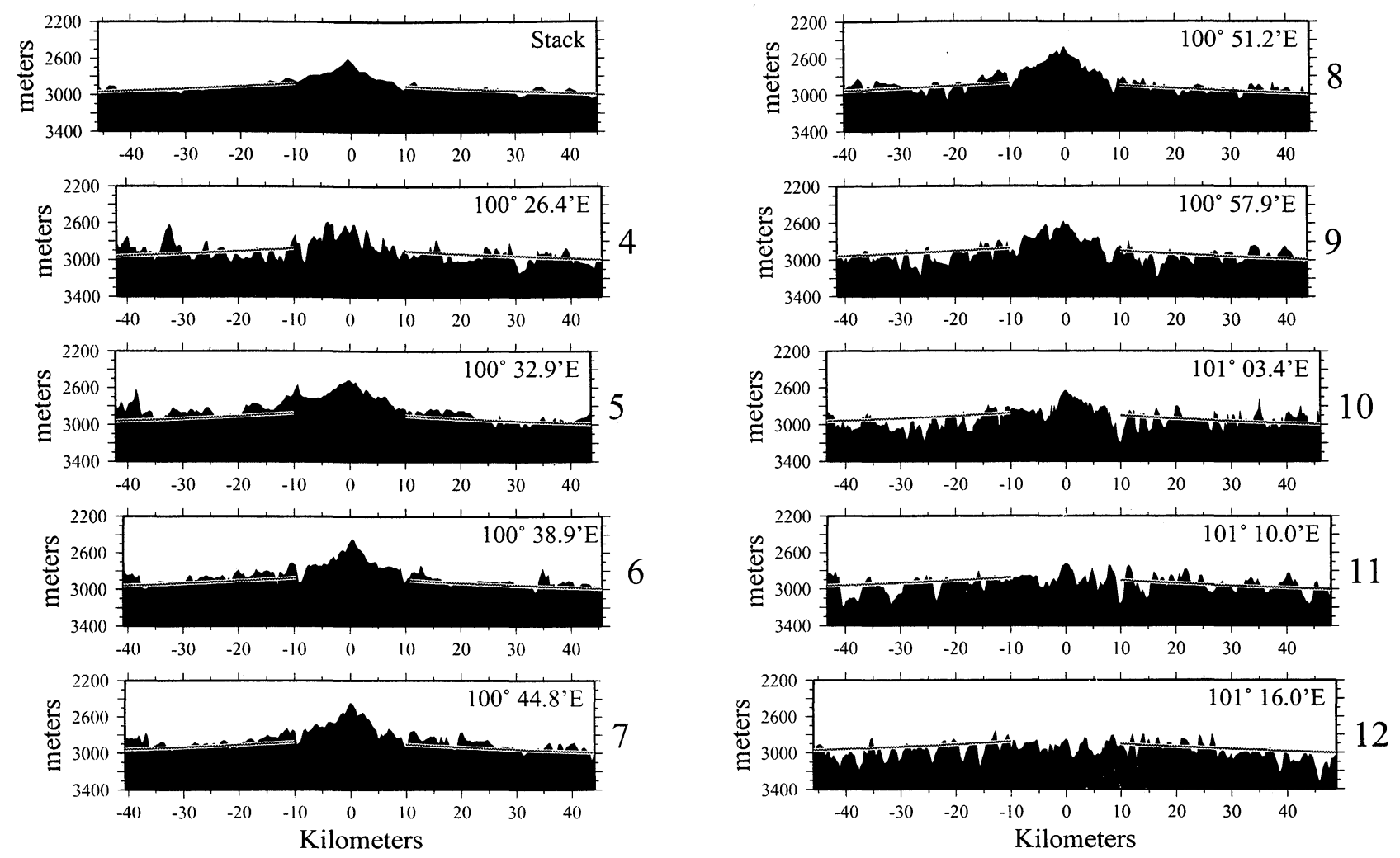

Figure 8. Bathymetric profiles across the axis from Segment P1 of the Southeast Indian Ridge. All profiles are projected parallel to the local spreading direction. The southern flank is to the left. The longitude at which each profile crosses the ridge axis is noted. Profile numbers correspond to those in Figure $6 \mathrm{~b}$, which shows the location of the profiles. A stacked profile is also shown. The square root of age subsidence curve which best fits the stacked profile is superimposed on each profile. The best fitting subsidence rates are $157.9 \mathrm{~m} / \mathrm{m} . \mathrm{y} .{ }^{1 / 2}$ for the north flank and $164.8 \mathrm{~m} / \mathrm{m} . \mathrm{y} .{ }^{1 / 2}$ for the south flank. Data from the southern flank of profile 4 was not used in the analysis of subsidence rates because of disturbed morphology.

that if the very vigorous hydrothermal circulation is confined to a narrow region at the axis, then subsidence on the ridge flanks beyond this narrow zone is greatly reduced.

The underlying premise of the model is that intense hydrothermal circulation constrained to the immediate vicinity (less than a few kilometers) of the axis extracts a very large amount of heat from the crust, resulting in a significantly reduced geothermal gradient within the cooled region. Off axis, the extremely vigorous circulation ceases and is replaced by much less efficient diffuse low-temperature hydrothermal flow. Conduction thus becomes a primary mechanism of heat transport on the ridge flanks. Heat transport by conduction is given by the product of the thermal conductivity and the temperature gradient. The very low geothermal gradient within the cooled crust therefore retards conductive cooling of the lithosphere on the ridge flanks and lowers the subsidence rate, since significantly less heat is lost from the lithosphere than calculated from simple conductive models such as those of Parsons and Sclater [1977].

Stein and Stein [1994] estimated that approximately one third of the global oceanic heat flux occurs by hydrothermal flow. They also calculated that $\sim 30 \%$ of the hydrothermal heat flow or $\sim 10 \%$ of the total flux occurs by active high-temperature circulation in crust less than $0.1-1 \mathrm{~m} . \mathrm{y}$. in age. Field observations indicate that high-temperature hydrothermal circulation is restricted to the immediate vicinity of the ridge axis. Therefore the crustal age to which active high-temperature circulation extends at intermediate and fast spreading ridges is probably closer to 0.1 m.y. (3 - $7 \mathrm{~km}$ from the axis) than 1 m.y. (30 - 70 $\mathrm{km}$ from the axis).

The remainder of the hydrothermal heat loss occurs over 50 $65 \mathrm{~m} . \mathrm{y}$. through low-temperature diffuse hydrothermal flow. Thus although more total heat is lost off axis, the rate at which heat is removed off axis is $<1 \%$ that at the axis. It is this huge difference in the efficiency of on-axis active high-temperature hydrothermal circulation and off-axis diffusive low-temperature hydrothermal circulation that drives our model.

The change in efficiency in hydrothermal circulation assumed in our model might be a result of several processes. A major factor is certainly the absence off axis of the shallow heat source provided by the presence of magma at the axis. Precipitation of minerals that clog pore spaces and reduce crustal permeability may also contribute to the reduced efficiency of heat transport [Bischoff, 1980; Sleep, 1983, 1991]. Such a porosity decrease has been proposed as an explanation of the tomographically observed increase in seismic velocities of the shallow crust away from the ridge axis at a segment of the Juan de Fuca Ridge [Sohn et al., 1997].

\subsection{Model Parameterization}

Full calculations of the effects of circulation of hot water through permeable media have been important in looking at what might control the spatial scale of hydrothermal flow [e.g., Davis 

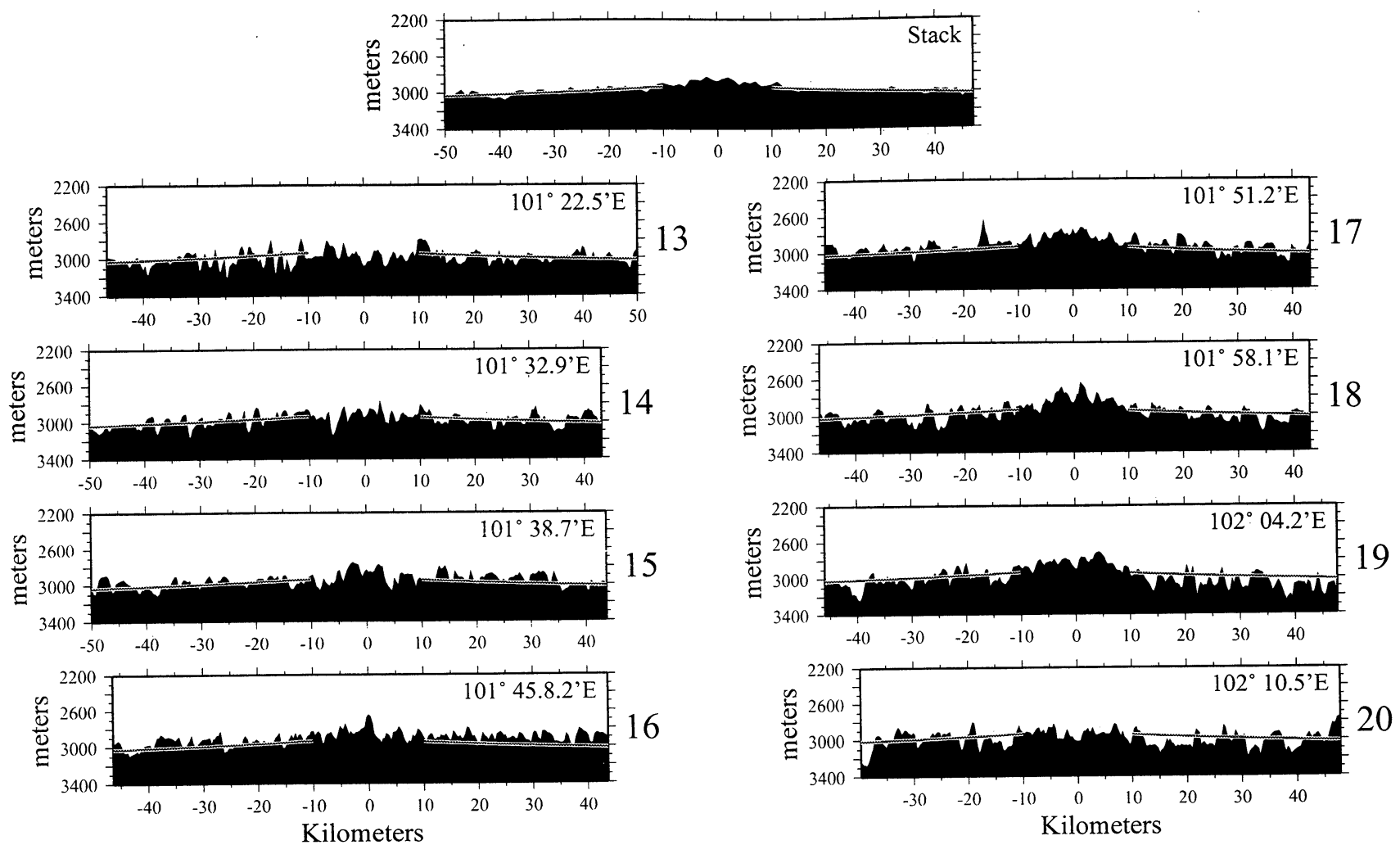

Figure 9. Bathymetric profiles across the axis of the Southeast Indian Ridge in Segment P2. All profiles are projected parallel to the local spreading direction. The southern flank is to the left. The longitude at which each profile crosses the ridge axis is noted. Profile numbers correspond to those in Figure $6 \mathrm{~b}$, which shows the location of the profiles. A stacked profile is also shown. The square root of age subsidence curve which best fits the stacked profile is superimposed on each profile. The best fitting subsidence rates are $118.9 \mathrm{~m} / \mathrm{m} . \mathrm{y} .^{1 / 2}$ for the north flank and $154.6 \mathrm{~m} / \mathrm{m} . \mathrm{y} .{ }^{1 / 2}$ for the south flank.

et al., 1996] as well as the timescale of hot "plume" events [Lowell and Germanovich, 1995]. Such complete calculations are computationally difficult and would be especially hard to couple to the larger-scale thermal structure of the lithosphere and asthenosphere. Thus the hydrothermal effects on heat transport have generally been parameterized in larger-scale models.

Two general approaches have been taken for estimating the average effects of hydrothermal circulation on the thermal structure of ridges. In one, the effect of heat extraction by water flow is treated in terms of heat sinks [e.g., Morton and Sleep, 1985]. This approach has the advantage that the amount of heat needed to produce a temperature structure that matches geologic and geophysical constraints is what is determined in the model, as well as something about the spatial distribution of those sinks. However, these models are difficult to use to predict the effects of changing variables such as the spreading rate or the crustal thickness.

In the other approach, the added cooling due to water flow is approximated using parameterized convection. ' In parameterized convection the effect of convection is simulated by solving the equation for temperature diffusion using an enhanced conductivity in the region where convection is assumed to occur. This approach is based on analysis of steady state convection in which physical parameters such as layer thickness and permeability can be related to the heat flux carried across a layer. In steady state, the increased heat carried by circulation can be matched by a model that neglects advection of heat, but takes the conductivity of the convecting layer to be increased relative to its normal value. The enhancement factor, called the Nusselt number, $\mathrm{Nu}$, is rigorously defined for a layer in a steady thermal state. The Nusselt number specifies the ratio of average vertical heat transport through a convecting layer to what would be transported by conduction alone.

Though there is no rigorous justification for using such a parameterized convection approach for a system that is not in steady state, it has proved useful in estimating the effect of hydrothermal cooling on the ridge thermal structure. The conductivity is taken to be enhanced by the Nusselt number in regions where the rock is thought to be permeable [e.g., Phipps Morgan et al., 1987; Lin and Parmentier, 1989; Chen and Morgan, 1990; Henstock et al., 1993]. In such models the average Nusselt number near the ridge is set to a large value $(>10)$ down to depth where cracks might close under pressure and so halt penetration of water. The Phipps Morgan and Chen [Phipps Morgan and Chen, 1993; Chen and Phipps Morgan, 1996] version of this kind of model can fit the general trend of deepening magma chambers with slower spreading rates.

\subsection{Model Calculations}

To investigate how a reduction in efficient heat transport might affect off-axis temperatures, lithospheric thickness, and subsidence, we show the results of simple one-dimensional thermal models in Figure 16. Figure 16a shows the isotherms 

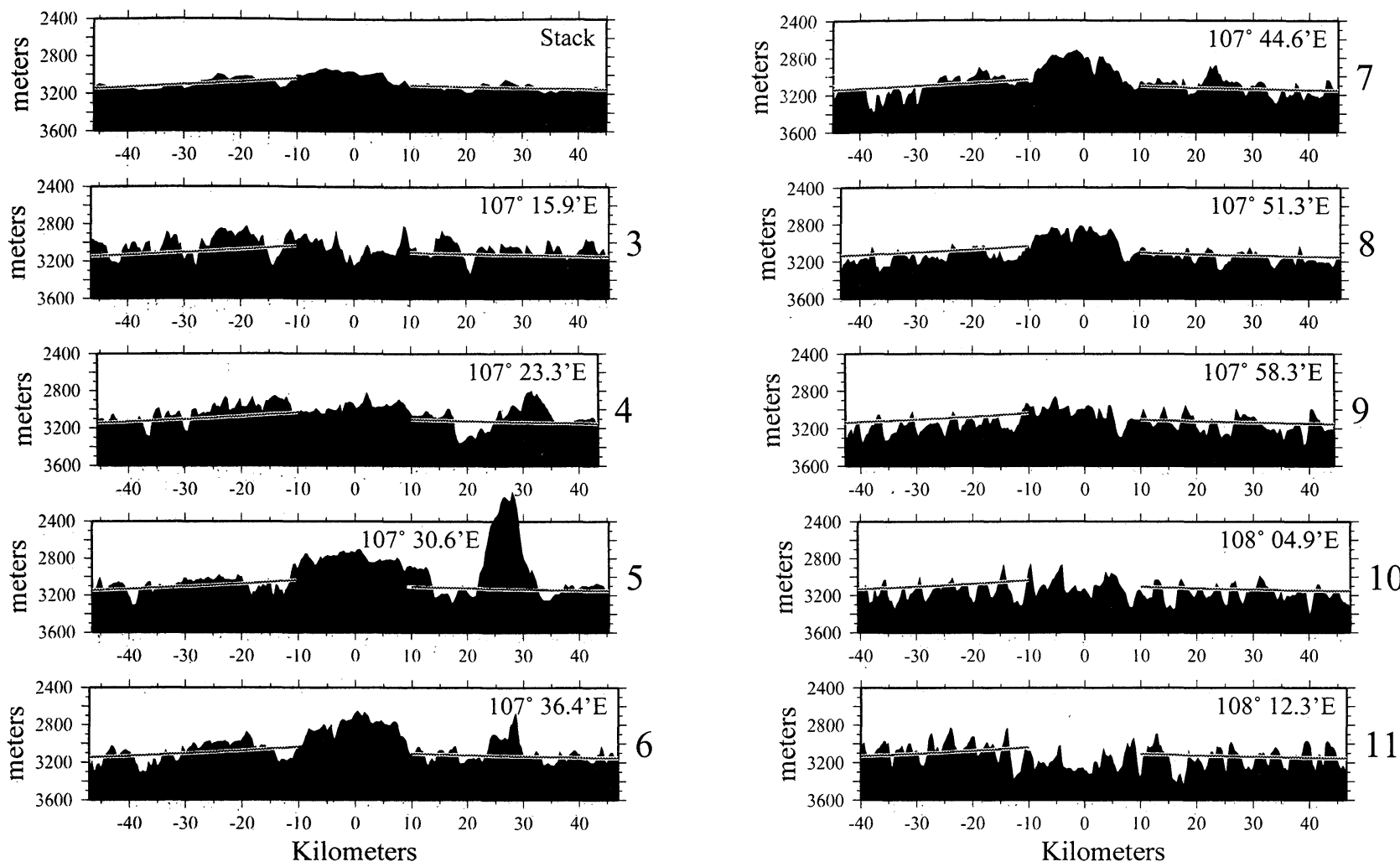

Figure 10. Bathymetric profiles across the axis of the Southeast Indian Ridge in Segment R. All profiles are projected parallel to the local spreading direction. The southern flank is to the left. The longitude at which each profile crosses the ridge axis is noted. Profile numbers correspond to those in Figure 6c, which shows the location of the profiles. A stacked profile is also shown. The square root of age subsidence curve which best fits the stacked profile is superimposed on each profile. The best fitting subsidence rates are $78.3 \mathrm{~m} / \mathrm{m} . \mathrm{y}^{1 / 2}$ for the north flank and $188.7 \mathrm{~m} / \mathrm{m}$. . $^{1 / 2}$ for the south flank. Data from the northern flank of profiles 4 and 5 were not used in the analysis of subsidence rates because of the presence of a large seamount.
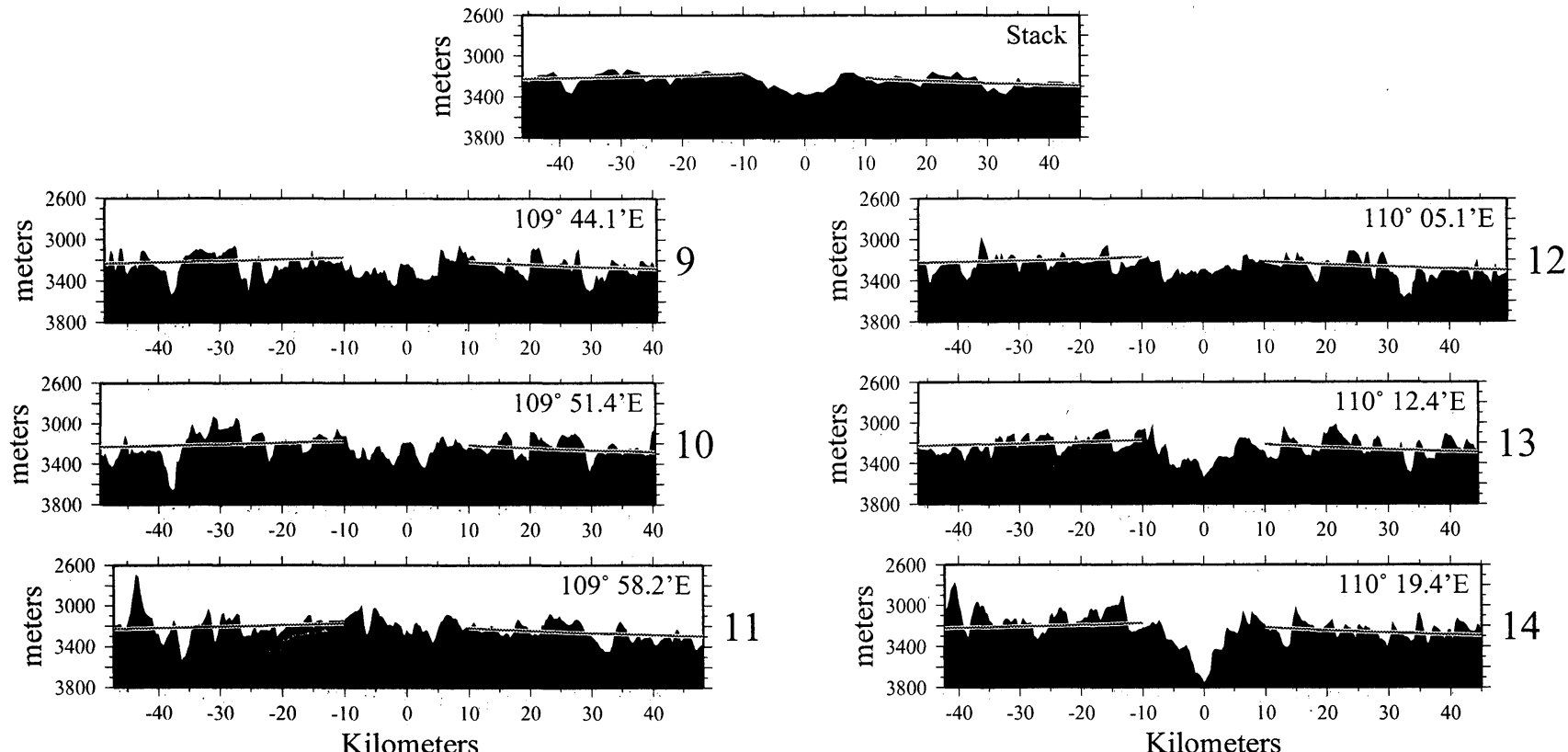

Figure 11. Bathymetric profiles across the axis of the Southeast Indian Ridge in Segment S1. All profiles are projected parallel to the local spreading direction. The southern flank is to the left. The longitude at which each profile crosses the ridge axis is noted. Profile numbers correspond to those in Figure $6 \mathrm{c}$, which shows the location of the profiles. A stacked profile is also shown. The square root of age subsidence curve which best fits the stacked profile is superimposed on each profile. The best fitting subsidence rates are $130.8 \mathrm{~m} / \mathrm{m} . \mathrm{y} .{ }^{1 / 2}$ for the north flank and $90.3 \mathrm{~m} / \mathrm{m} . \mathrm{y} .{ }^{1 / 2}$ for the south flank. 


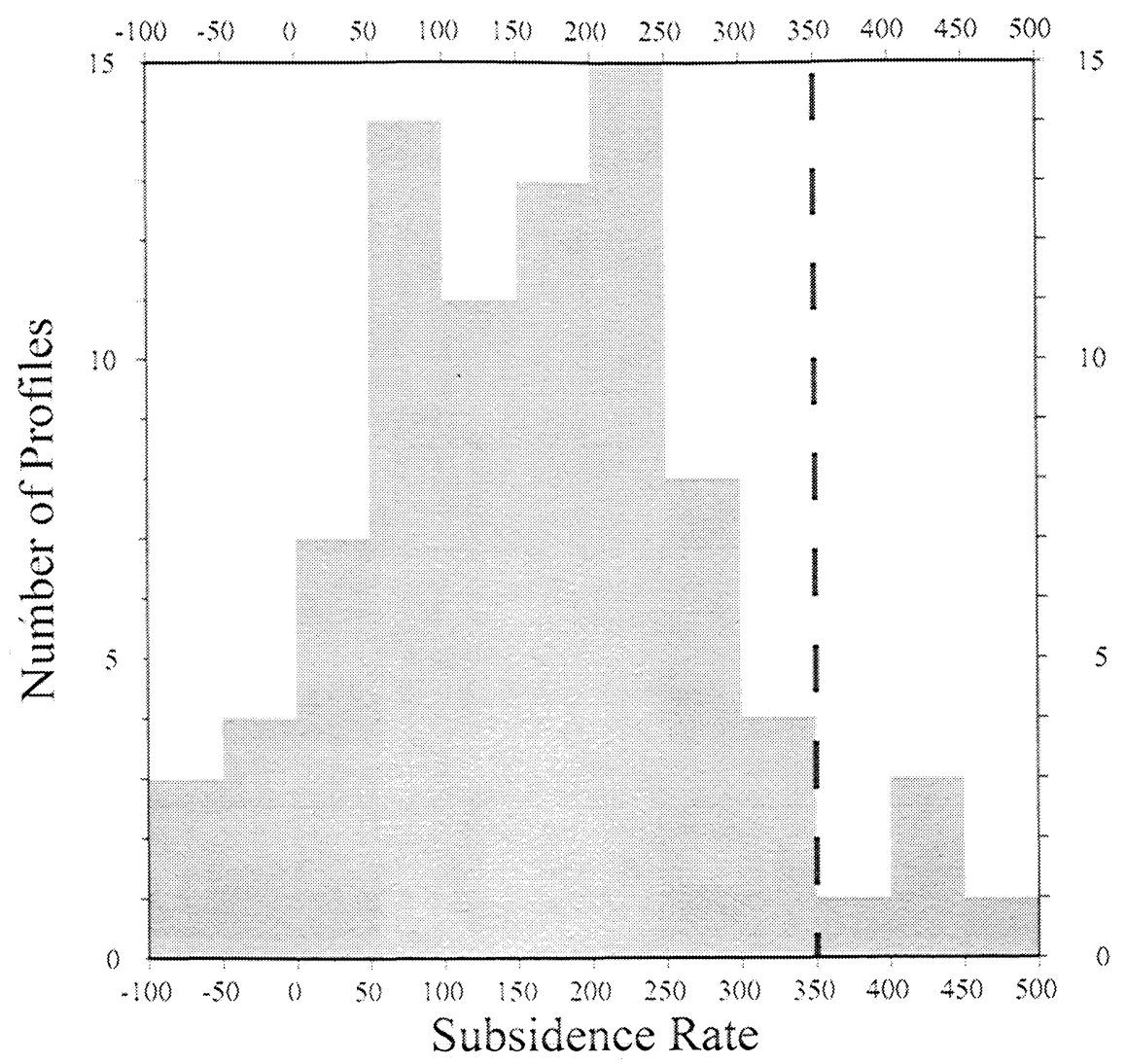

Figure 12. Histogram showing the distribution of subsidence rates obtained from bathymetry profiles across the Southeast Indian Ridge crest (Figures 7 - 11). Subsidence rate estimates were obtained for each flank of the profiles using data $>10 \mathrm{~km}$ from the ridge axis. The heavy dashed line shows the average global long-term ridge flank subsidence rate of $350 \mathrm{~m} / \mathrm{m} . \mathrm{y} .{ }^{1 / 2}$ [Parsons and Sclater, 1977]. The mean of these samples is $161 \mathrm{~m} / \mathrm{m} . \mathrm{y} .{ }^{1 / 2}$ and the $99 \%$ confidence interval for the mean subsidence rate is $126.9-195.1 \mathrm{~m} / \mathrm{m} . \mathrm{y} .^{1 / 2}$.

resulting from purely conductive cooling. Figure $16 \mathrm{~b}$ shows the results of a model that includes a region of vigorous hydrothermal circulation near the ridge axis. In this model a layer of thickness $h$ is initially taken to have a diffusivity that is $N u$ times the normal value of $1 \times 10^{-6} \mathrm{~m}^{2} / \mathrm{s}$. This layer and the half-space that it overlies are initially at a temperature of $1300^{\circ} \mathrm{C}$, and the surface is maintained at $0^{\circ} \mathrm{C}$. We neglect the latent heat of magma crystallization since we want to illustrate how changes in the efficiency of heat extraction affect off-axis subsidence. After $0.1 \mathrm{~m} . \mathrm{y}$. of cooling (about $3.5 \mathrm{~km}$ from the spreading axis for the SEIR or about $7 \mathrm{~km}$ from the axis for the SEPR), the enhanced conductivity is switched off (i.e., the Nusselt number of the top layer is set to 1 so that normal conduction is simulated in the now cooled layer). The change in the efficiency of the hydrothermal circulation was set at a given age rather than at a particular distance from the axis simply for convenience, since the $\mathrm{x}$ axis in our calculations is actually time. The choice of $0.1 \mathrm{~m}$.y. was based on the fact that $0.1 \mathrm{~m} . \mathrm{y}$. is a convenient value which results in the zone of intense hydrothermal activity being a few kilometers wide.

We use an explicit finite difference method to solve for the temporal changes in temperature with depth. Figure 16 compares the predicted pattern of isotherms for a model with no enhanced conduction and one where the top 7-km layer is given an initial Nusselt number of 20. Figure 17a shows how different the model geotherms are after $0.1 \mathrm{~m} . \mathrm{y}$. for a case with normal conduction
$(N u=1)$ and one where the top $7-\mathrm{km}$ has $N u=20$. Figure $17 \mathrm{~b}$ illustrates how temperatures evolve for the case shown in Figure $16 \mathrm{~b}(h=7 \mathrm{~km}$ and $N u=20$ for the first $0.1 \mathrm{~m} . \mathrm{y}$., following which the Nusselt number is set to 1 ). This shows that $0.2 \mathrm{~m}$.y. after the enhanced conductivity is "turned off", temperatures at depths greater than $\sim 8 \mathrm{~km}$ have decreased, while they increased at shallower depths. A significant amount of the heat conducted up from the hot mantle (asthenosphere) has been utilized to reheat the lower crust. The surface thermal gradient stays low during this period and is significantly lower than that resulting from conductive cooling.

Heat loss from the lithosphere and subsidence over this period of time are considerably less than for a conductive model. Figure 18 shows the local isostatic subsidence resulting from our model (again with $h=7 \mathrm{~km}$ and $N u=20$ for the first $0.1 \mathrm{~m} . \mathrm{y}$.), as well as the subsidence predicted from a simple conductive model. The subsidence is computed as described by Turcotte and Schubert [1982] with parameters set to give a conductive subsidence rate of $350 \mathrm{~m} / \mathrm{m} . \mathrm{y} .^{1 / 2}$. The subsidence rate is significantly less for our model from 0.1 to $1 \mathrm{~m} . \mathrm{y}$. Figure 18 also shows the subsidence which results if the very vigorous hydrothermal circulation $(N u=20$ to a depth of $7 \mathrm{~km})$ continues far away from the axis. It can be seen that an important constraint for producing low subsidence rates on the ridge flanks is that the very vigorous crustalscale convective heat removal be restricted to a narrow area near the axis. 


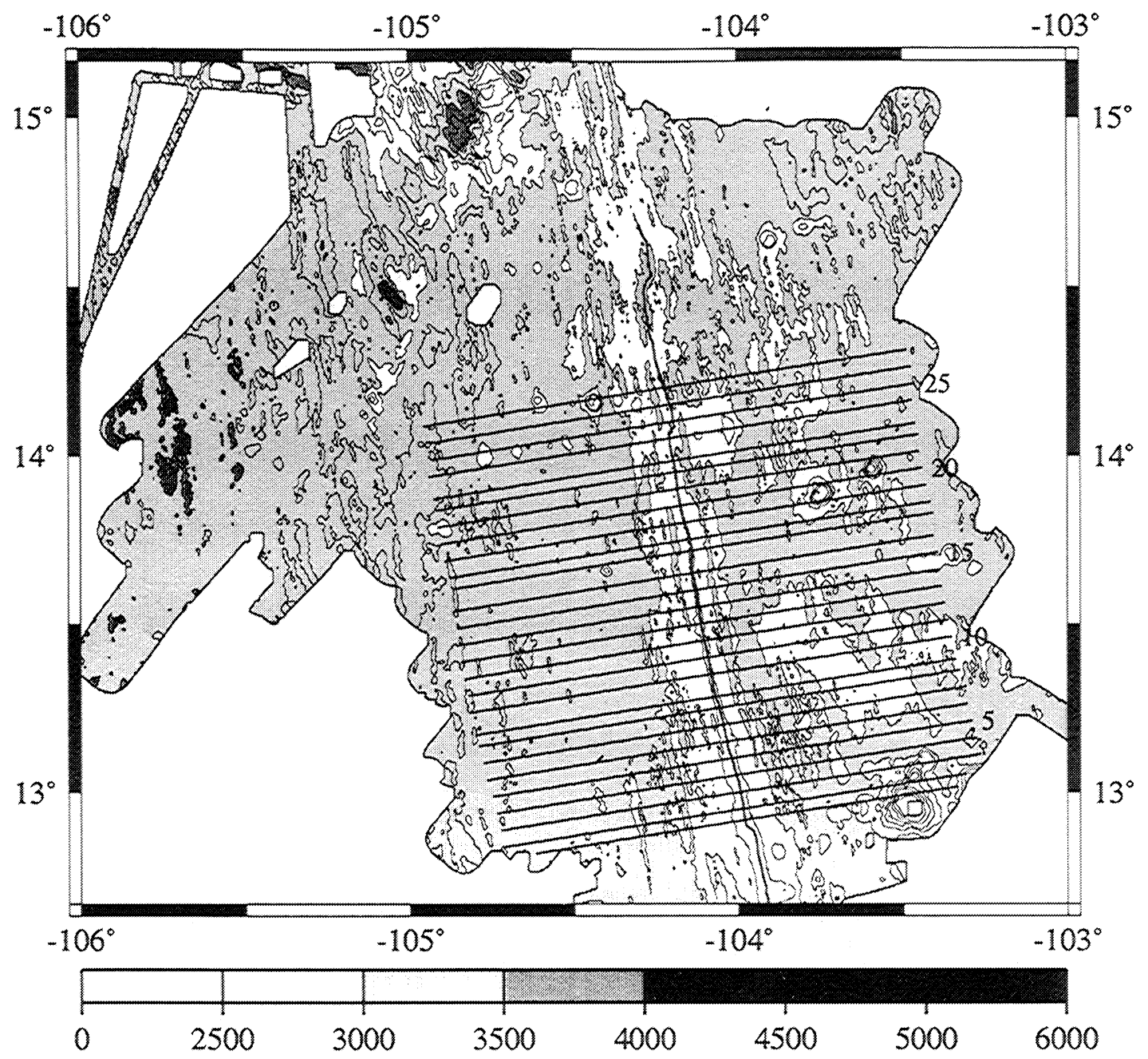

Figure 13. Bathymetry map of the northern East Pacific Rise between $12^{\circ} 40^{\prime} \mathrm{N}$ and $15^{\circ} 10^{\prime} \mathrm{N}$, constructed from gridded SeaBeam and SeaMARC II data [Macdonald et al., 1992]. Contour interval is $250 \mathrm{~m}$, and shading changes at $500-\mathrm{m}$ intervals. The ridge axis is shown by a solid line. Solid lines across the axis show the location of profiles shown in Figure 14. Profile numbers correspond to those in Figure 14. The total spreading rate is $91-96 \mathrm{~mm} / \mathrm{yr}$.

Figure 19 shows the best fitting subsidence rate, assuming a linear relationship between subsidence and the square root of plate age, for a range of model parameters. In all cases the enhanced near-axis conductivity (with the enhancement factor given by the Nusselt number) is "turned off" at 0.1 m.y. Two curves are shown, for 5- and 7-km-thick upper layers within which the Nusselt number is initially high. The least squares estimated subsidence rate is computed from the model output between 0.1 and $1 \mathrm{~m} . \mathrm{y}$. times. To match the observations presented earlier in this paper, an initial Nusselt number in the range of $15-30$ is required, depending on the thickness of the "hydrothermal layer".

The model thermal structure shown in Figure $16 \mathrm{~b}$ is very similar to the near-axis thermal structure deduced by Dunn et al. [2000] from seismic tomographic inversion at $9^{\circ} 30^{\prime} \mathrm{N}$ on the EPR. Dunn et al. [2000] inverted travel time data to obtain the velocity distribution beneath the ridge axis and then used this information to estimate isotherms. In their temperature models, the depth to the $800^{\circ} \mathrm{C}$ isotherm increases from about $1 \mathrm{~km}$ at the axis to $>6 \mathrm{~km}$ at a distance of $3 \mathrm{~km}$ from the axis. Farther from the axis, isotherms within the crust are nearly flat out to the edge of their data ( $10 \mathrm{~km}$ from the axis). Both the rapid cooling of the crust and the flat isotherms away from the axis are consistent with our hypothesis, based on subsidence rates, of a zone of vigorous hydrothermal cooling restricted to a region within a few kilometers of the ridge axis.

The subsidence curve shown for our model in Figure 18 includes very rapid subsidence of about $350 \mathrm{~m}$ within a few kilometers of the axis in the region of extremely vigorous hydrothermal activity. This modeled subsidence is similar in magnitude and width to the axial high observed at fast spreading ridges. This appears to suggest that the axial high may result from this rapid cooling. However, other observations suggest that this is not the case, and that the axial high is a dynamic feature rather than a result of thermal subsidence. One such observation is that at intermediate and fast spreading ridge segments where there is a large variation in axial depth within a segment, the depth variation is not observed on the ridge flanks near the axis [Ma and Cochran, 1997]. An example is given in Figure 20, which shows along-axis and axis-parallel depth profiles for Segment M3 on the 

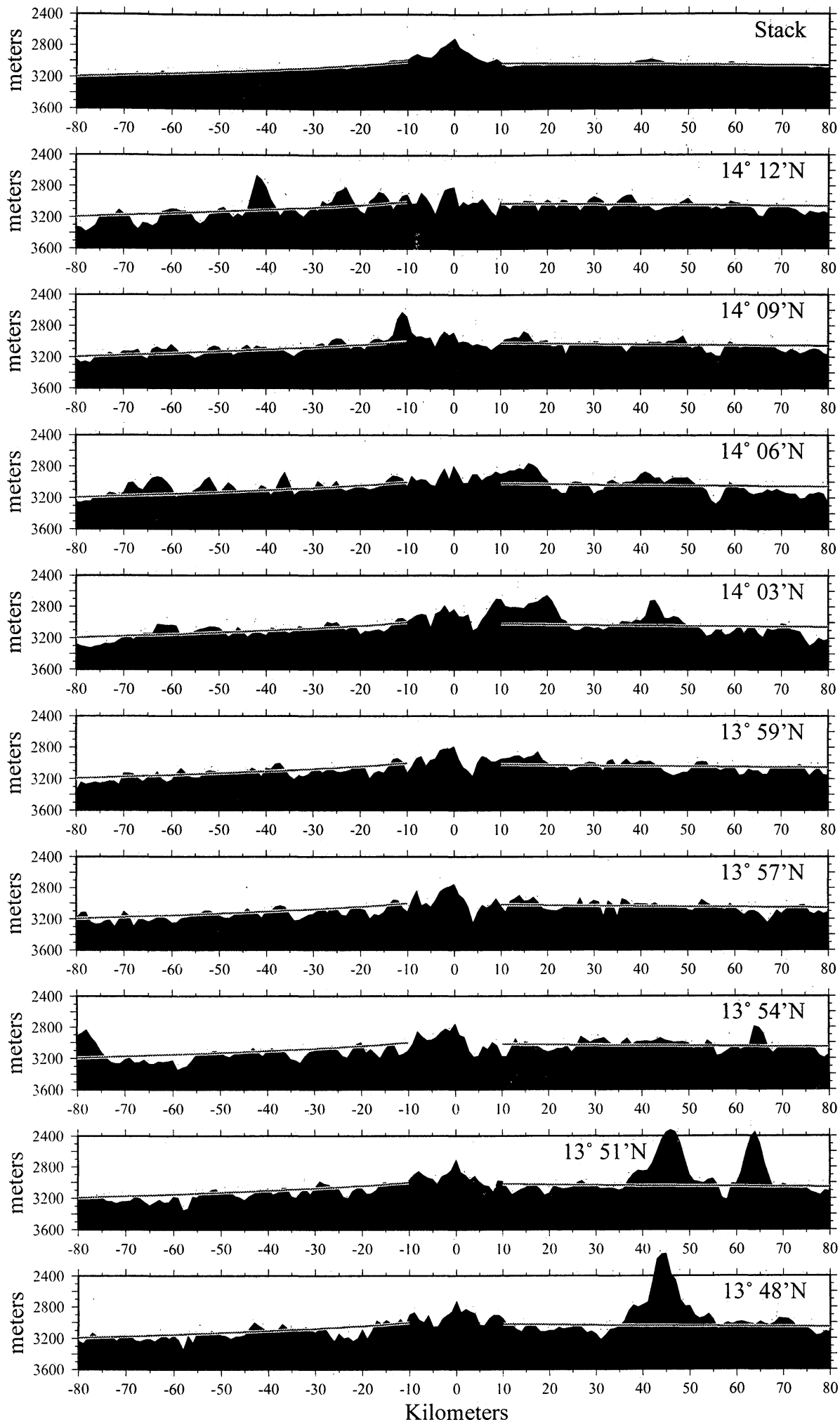

Figure 14. Bathymetric profiles across the axis of the northern East Pacific Rise between $12^{\circ} 55^{\prime} \mathrm{N}$ and $14^{\circ} 12^{\prime} \mathrm{N}$. All profiles are projected parallel to the local spreading direction. The western flank is to the left. The latitude at which each profile crosses the ridge axis is noted. Profile numbers correspond to those in Figure 13, which shows the location of the profiles. A stacked profile is also shown. The square root of age subsidence curve which best fits the stacked profile is superimposed on each profile. The best fitting subsidence rates are $225.7 \mathrm{~m} / \mathrm{m} . \mathrm{y} .{ }^{1 / 2}$ for the west flank and $43.7 \mathrm{~m} / \mathrm{m} . \mathrm{y} .{ }^{1 / 2}$ for the eastern flank. Large seamounts or disturbed morphology precluded use of the western flank of profile 2 , and the eastern flank of profiles 1-3, 19, 20, and 24 in construction of the stacked profile or analysis of subsidence rates. 

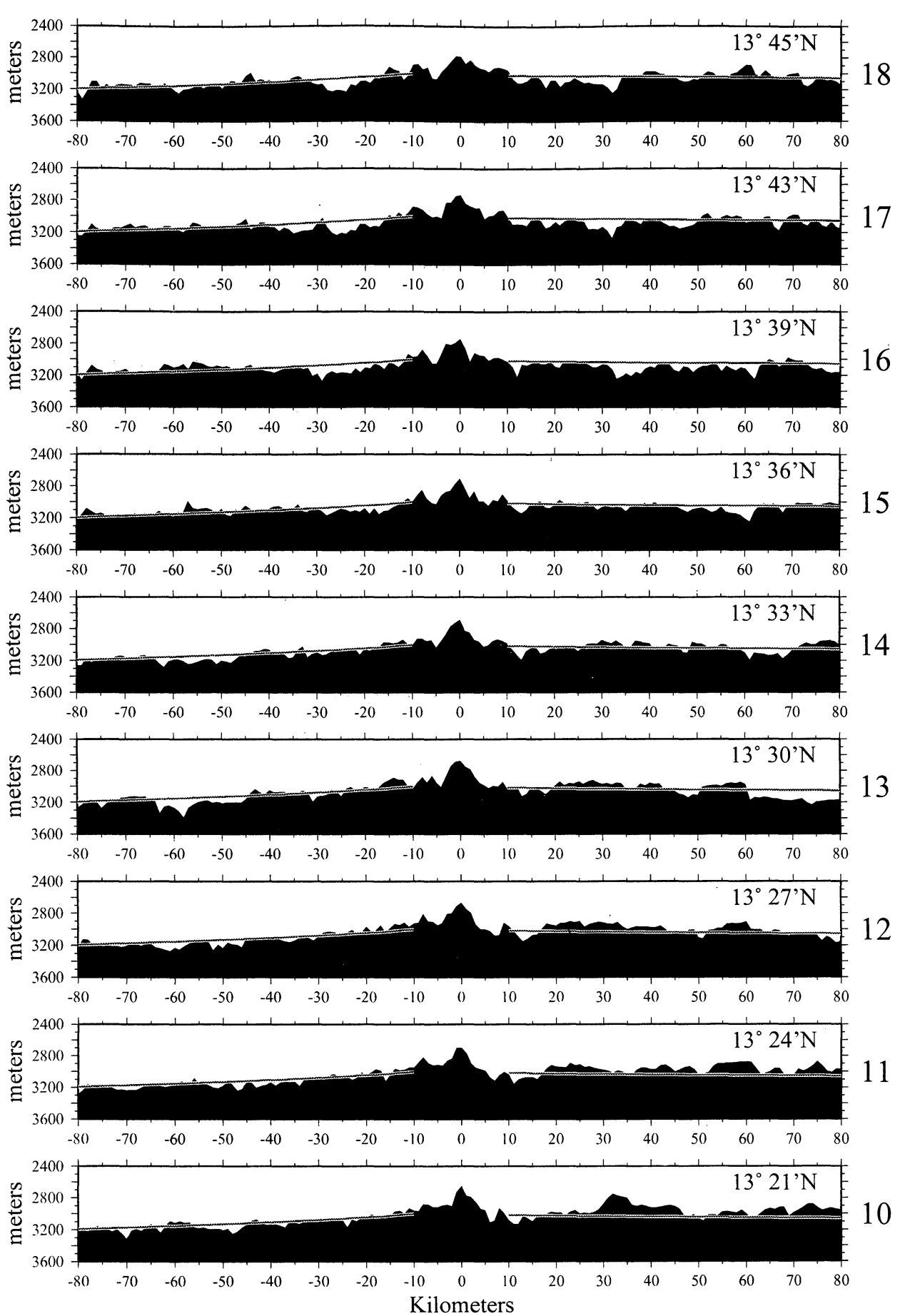

Figure 14. (continued)

SEIR (Figure 6a). The several hundred meter depth variation observed in the axial profile is not present off axis. Since there is not a systematic variation in ridge flank subsidence rates accompanying the systematic variation in the relief of the axial high, the axial high relief can not be related to the subsidence history, but rather is related to some other axially centered process. Also, the observed subsidence rates at segments such as P2 and S1 where there is not an axial high are not greater than at Segments M3 and P1 with an axial high, as would be expected if the axial high results from rapid extraction of heat near the axis. The several hundred meters of subsidence which we model in the immediate vicinity of the axis during the period of vigorous cool- ing is not observed. This is probably due to the fact that axial high-temperature hydrothermal circulation is more intense and more concentrated at the axis than we have modeled, so that the axis never reaches the zero bathymetric level of the models.

\section{Discussion}

\subsection{Crustal-Scale Hydrothermal Circulation}

An important requirement of the model that we have just presented is that vigorous hydrothermal circulation extends through the entire crust very close to the ridge axis. There are several lines of observational evidence indicating vigorous hydrothermal 

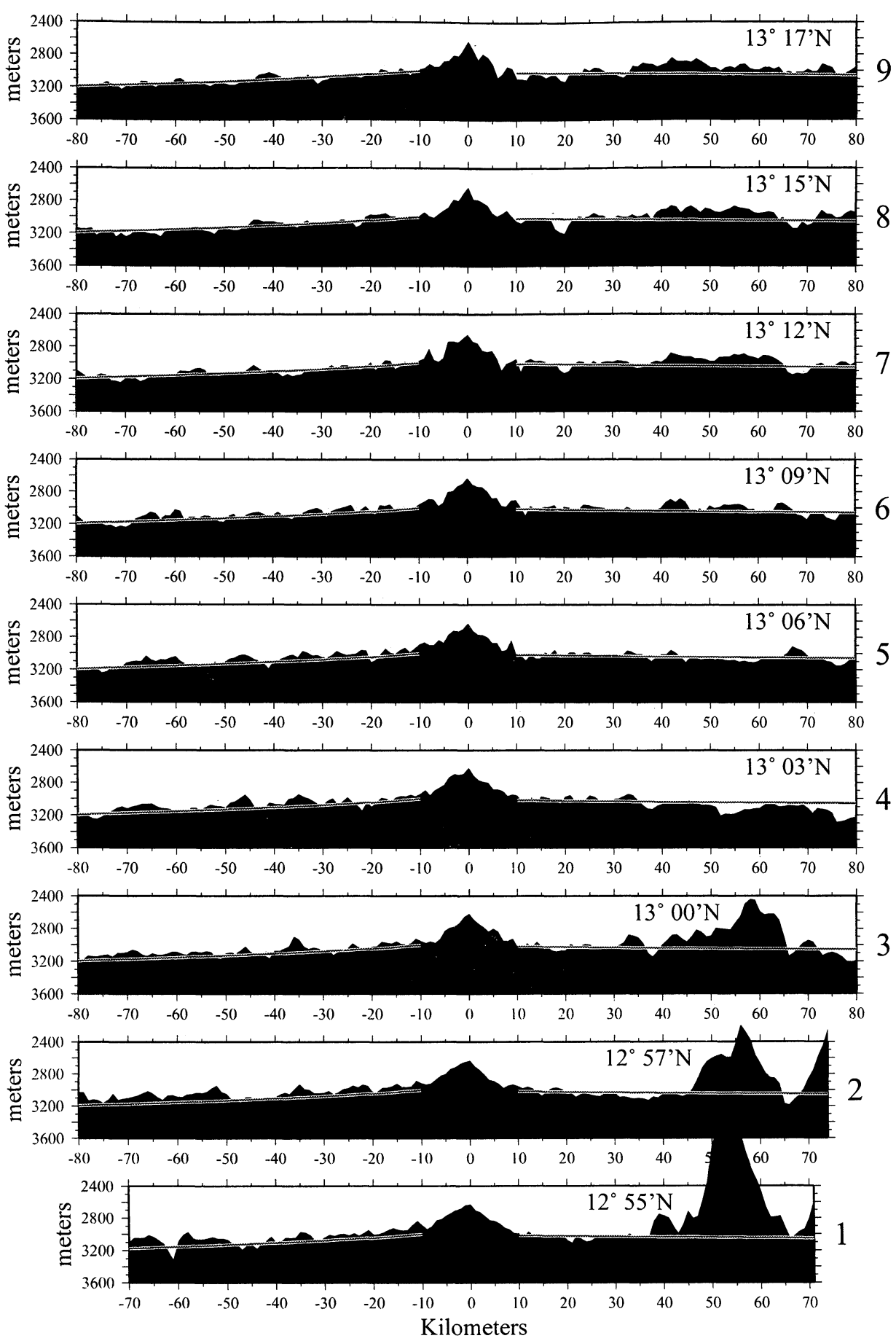

Figure 14. (continued)

circulation at and close to mid-ocean ridges. One is the existence of active black and white smoker vents seen on some ridges emitting high-temperature fluids [e.g., Rona et al., 1986; Von Damm, 1990, 1995]. Another is the fact that the axial magma chambers imaged seismically along most fast and some intermediate spreading rate ridges [e.g., Detrick et al., 1987; Morton et al., 1987; Mutter et al., 1995] are deeper than the predicted bottom of the cool lithosphere based on conductive thermal models of ridges [e.g., Phipps Morgan et al., 1987; Lin and Parmentier, 1989]. Also, the pattern of alteration and infilling of pore space by hydrothermal minerals observed in oceanic boreholes and around massive sulfide deposits in ophiolites are consistent with the flow of large volumes of water through the crust [e.g., Gillis and Robinson, 1990].

Ophiolite studies suggest that near-axis axis hydrothermal circulation may extend through most of the crust. Gregory and Taylor [1981] described oxygen isotope studies in the Oman ophiolite showing penetration of seawater down to the mantle section in an area where the crust has its full $(>5 \mathrm{~km})$ thickness and concluded that "deep hydrothermal circulation of seawater 


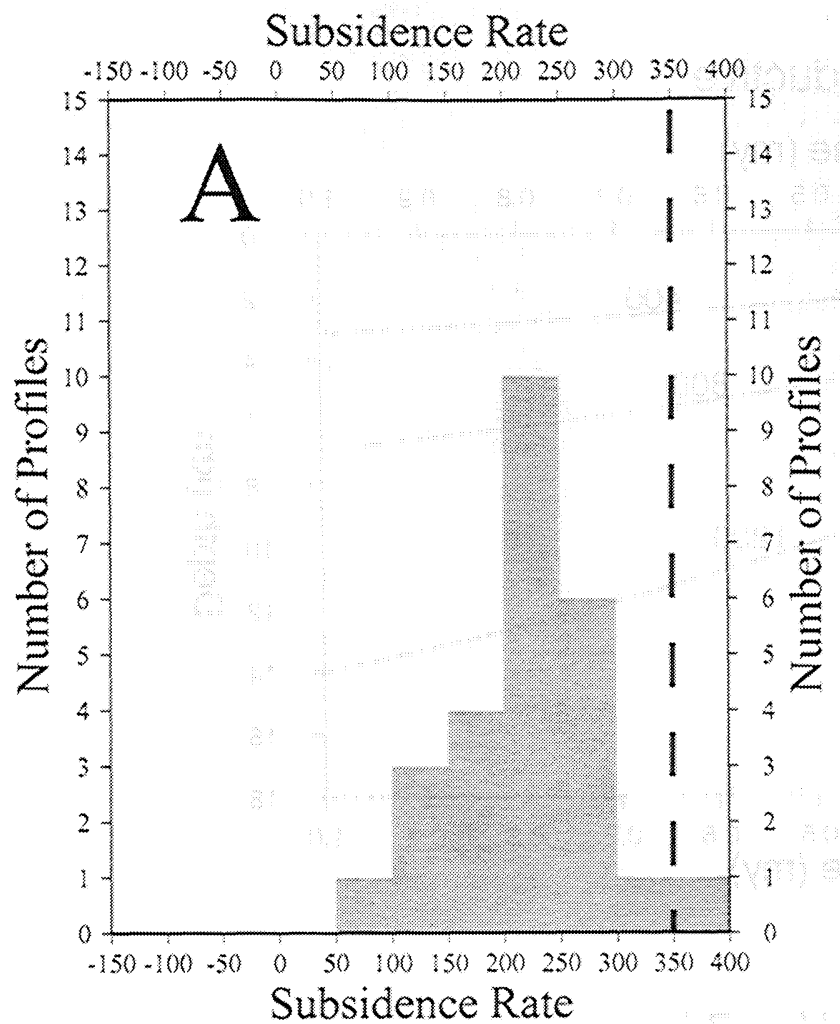

Figure 15a. Histogram showing the distribution of subsidence rates obtained from bathymetry profiles on the western flank of the northern East Pacific Rise (Figures 13 - 14). Subsidence rate estimates were obtained from the western flank of each profile (Figure 14) using data $>10 \mathrm{~km}$ from the axis. The heavy dashed line shows the average global long-term ridge flank subsidence rate of $350 \mathrm{~m} / \mathrm{m} . \mathrm{y} .{ }^{1 / 2}$ [Parsons and Sclater, 1977]. The mean of these samples is $221 \mathrm{~m} / \mathrm{m} . y .^{1 / 2}$ and the $99 \%$ confidence interval for the mean subsidence rate is $196.1-245.9 \mathrm{~m} / \mathrm{m} . \mathrm{y} .^{1 / 2}$.

has affected most of the feldspar-bearing rocks of the Samail ophiolite, including a large portion of the section that is equivalent to oceanic layer 3" [Gregory and Taylor, 1981, p.2752]. Similarly, Nehlig and Juteau [1988, p.199] found that "petrological and mineralogical data show that the whole crust, down to the petrological Moho, has been affected by a hydrothermal metamorphism, pervasive in the sheeted dyke complex and high-level isotropic gabbros and more localized around fractures in the underlying plutonic units".

Obviously, where there is an axial magma chamber (AMC), hydrothermal circulation at the axis cannot extend below the depth of the AMC. However, ophiolite studies suggest that deep circulation does occur very near the axis. Unpublished field observations in Oman by the Montpellier group show that "in the gabbro, there is obviously penetration of water close to the axis, in incompletely crystallized or recently crystallized gabbros (pegmatic recrystallized gabbros, amphibolite-rich gabbros, veins with epidote and various other hydrothermal minerals, etc.)... and sometimes quite deep in the gabbroic crust" (B. Ildefonse, personal communication, 1999). These observations suggest that pervasive hydrothermal circulation within layer 2 and extensive localized hydrothermal circulation at least to the depth of the Moho occur near the ridge axis

\subsection{Implications for Lithospheric Thickness and the Formation of Axial Morphology}

The strength of the lithosphere, or equivalently its effective elastic thickness $\left(T_{e}\right)$, is controlled by the temperature structure and is often defined in terms of the depth to a given isotherm [e.g., Watts, 1978; Bodine et al., 1981]. The thermal structure shown in Figure 16b implies that the lithosphere is thin and weak right at the axis, but thickens rapidly in the first several kilometers from the axis. This lithospheric thermal structure has implications for the formation of axial morphology. Specifically it is not compatible with most existing models for the formation of axial highs. By axial high we refer to the 300- to 400-m-high, 15 to $20 \mathrm{~km}$ wide bathymetric high found at the axis of most fast and some intermediate spreading rate ridges (See Figures 2, 7, 8, and 14).

The most widely used current model considers the axial high to be supported by a narrow column of buoyant material directly below the axis [Madsen et al., 1984; Kuo et al., 1986; Wilson, 1992; Wang and Cochran, 1993; Magde et al., 1995]. Since, in this model, the axial high is basically the flexural response of the lithosphere to the subsurface load of the buoyant region, its width and shape are controlled by the strength of the lithosphere. Wang and Cochran [1993] found that to reproduce the shape of the ax-

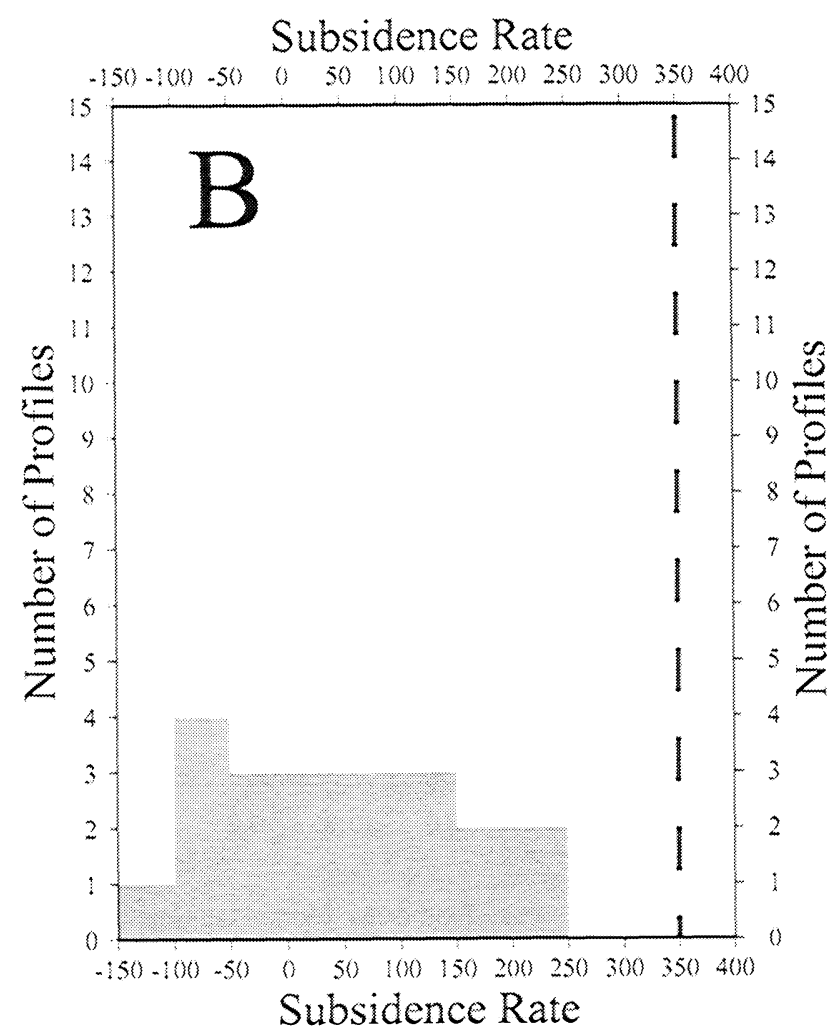

Figure 15b. Histogram showing the distribution of subsidence rates obtained from bathymetry profiles on the eastern flank of the northern East Pacific Rise (Figure 13). Subsidence rate estimates were obtained from the eastern flank of each profile (Figure 14) using data $>10 \mathrm{~km}$ from the axis. The heavy dashed line shows the average global long-term ridge flank subsidence rate of $350 \mathrm{~m} / \mathrm{m} . \mathrm{y} .1 / 2$ [Parsons and Sclater, 1977]. Subsidence rate estimates are evenly distributed between $-100 \mathrm{~m} / \mathrm{m} . \mathrm{y} .{ }^{1 / 2}$ and $225 \mathrm{~m} / \mathrm{m} . \mathrm{y}^{1 / 2}$ and are significantly lower than those obtained from the western flank (Figure 15a). 
A.

Conductive
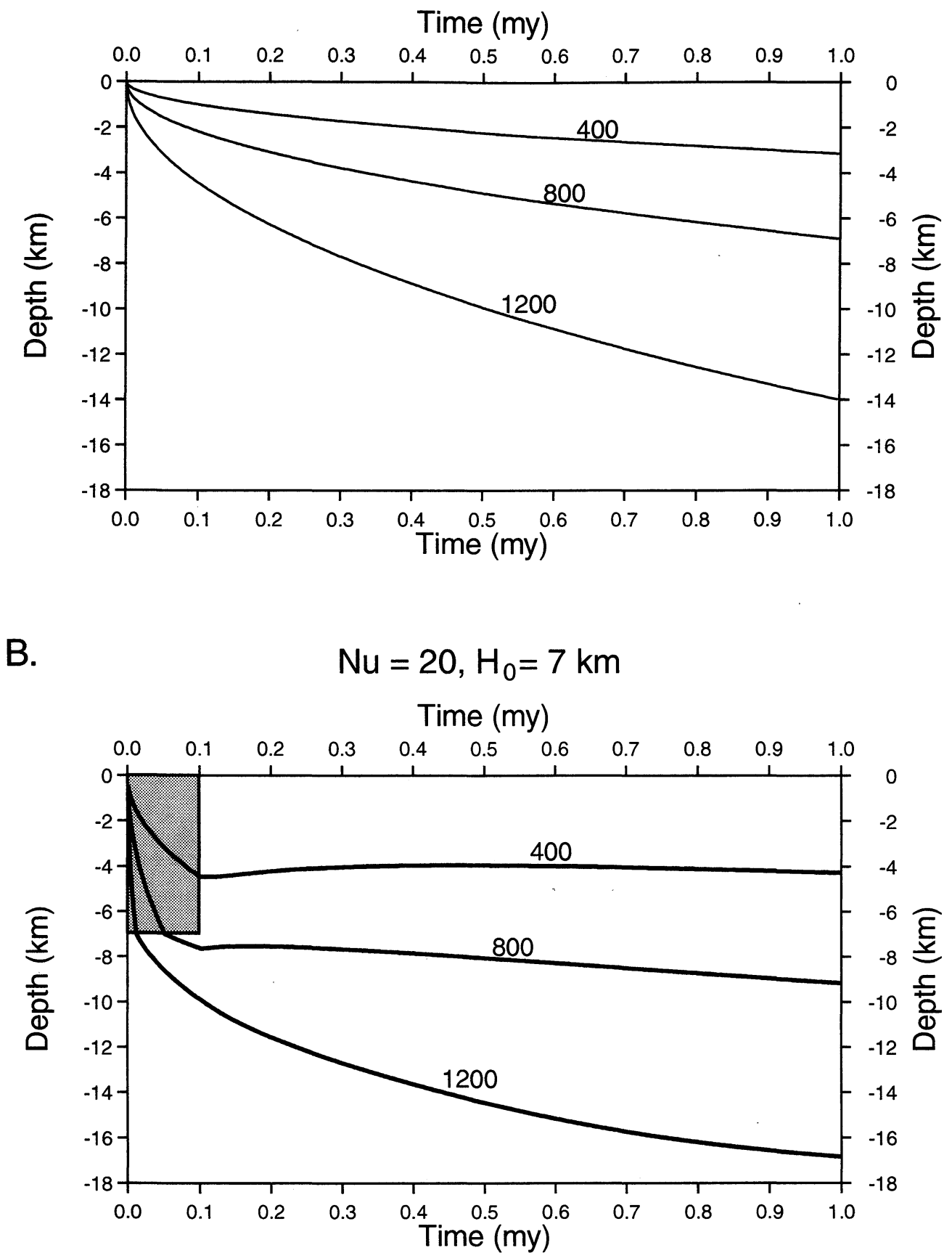

Figure 16. (a) Isotherms plotted against depth and time for a one-dimensional conductive cooling model. Parameters are given in the text. (b) Isotherms for a one-dimensional model including enhanced conductivity restricted to a region near the axis shown by the shaded box in the upper left corner. Here the Nusselt number is 20 between the surface of the crust and a depth of $7 \mathrm{~km}$ from the axis out to an age of $0.1 \mathrm{~m} . \mathrm{y}$. Everywhere else the conductivity is not enhanced (i.e. $N u=1$ ). Note that the isotherms deepen rapidly in the region of high Nusselt number (Figure 16b), and that the shallow isotherms are much flatter for crust of age $>0.1 \mathrm{~m} . \mathrm{y}$. for the case shown in Figure $16 \mathrm{~b}$ than for purely conductive cooling (Figure 16a).

ial high at the southern EPR (Figures. 1 and 2), it is necessary to assume the presence of a thin lithosphere at the axis $\left(T_{e}<\sim 0.5\right.$ $\mathrm{km})$ which thickens very slowly with distance from the axis (1 $\mathrm{km}$ increase in $T_{e}$ in 10-25 km from the axis).

Eberle and Forsyth [1998] presented an alternative model in which the axial high results from horizontal viscous shear stresses in the midcrust driven by plate separation. These stresses create a bending moment that supports the axial high. This model is conceptually similar to "necking" models for the formation of axial valleys [e.g., Tapponnier and Francheteau, 1978; Phipps Morgan et al., 1987]. In fact, Eberle and Forsyth [1998] found that that their model produced an axial high for a thin axial 
$\mathrm{Nu}=1,20 ; \mathrm{t}=.1$

A.

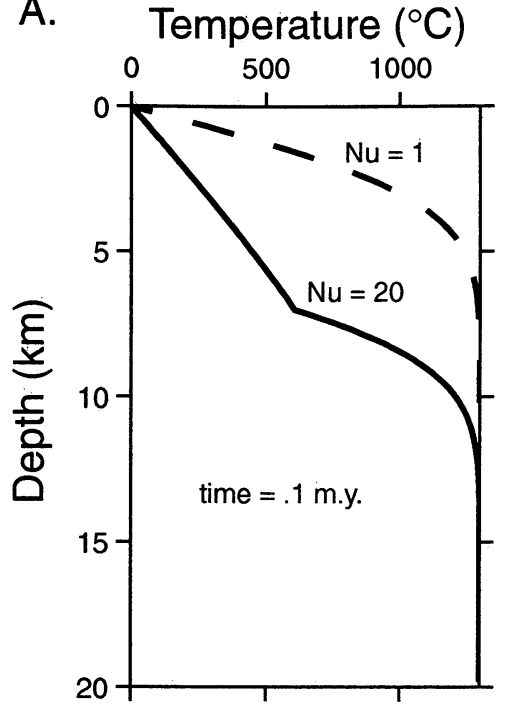

$\mathrm{Nu}=20, .1 \& .3 \mathrm{~m} . \mathrm{y}$.

B. Temperature $\left({ }^{\circ} \mathrm{C}\right)$

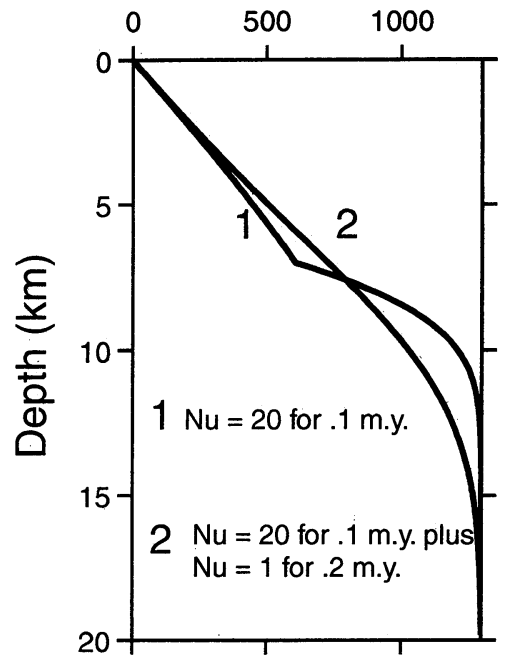

Figure 17. (a) Comparison of temperature-depth profiles for the two models shown in Figure 16 at a time of 0.1 m.y. The dashed line shows temperature with depth for the case of purely conductive cooling (Figure 16a) and the solid line shows temperature with depth for enhanced conductivity to a depth of $7 \mathrm{~km}$ (Figure 16b). (b). Comparison of temperature-depth profiles at two different times for the model shown in Figure 16b. Profile 1 is after $0.1 \mathrm{~m}$.y. cooling with enhanced near-axis conductivity to a depth of $7 \mathrm{~km}$, and is identical to the solid curve in Figure $17 \mathrm{a}$. Profile 2 is after an additional $0.2 \mathrm{~m}$.y. of cooling with no region of enhanced conductivity. Note that the lower crust $(\sim 3-7 \mathrm{~km}$ depth) has been reheated during this time interval.

lithosphere that does not thicken rapidly away from the axis, while it produces an axial valley if the axial lithosphere is thicker or thickens rapidly.

The isotherms in Figure 16b, as well as those deduced by Dunn et al. [2000] from their tomography experiment, are

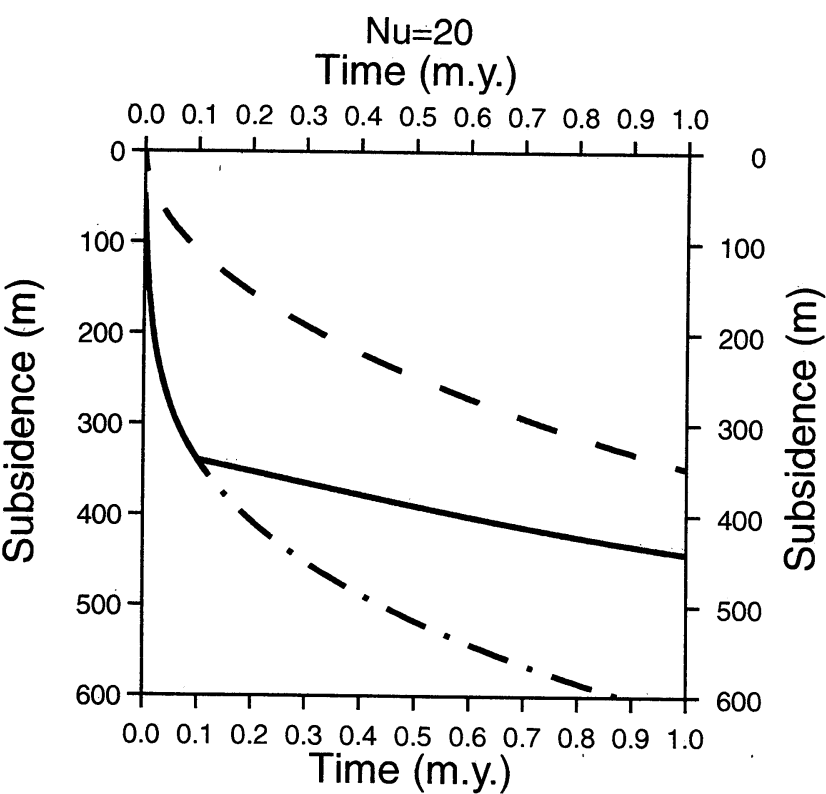

Figure 18. Model subsidence curves for three thermal models. The dashed line shows the purely conductive case (Figure 16a). The solid line shows the case with enhanced conductivity $(\mathrm{Nu}=$ 20) to a depth of $7 \mathrm{~km}$ for the first $0.1 \mathrm{~m}$.y. followed by purely conductive cooling $(N u=1)$ (Figure $16 \mathrm{~b})$. Note the very low subsidence rate for this model for times from 0.1 to $1.0 \mathrm{~m} . \mathrm{y}$. The dash-dot line shows subsidence for the case where the enhanced conductivity is not "turned off" after $0.1 \mathrm{~m}$.y. incompatible with both of these models. A new class of model has recently been developed in which the axial high results from accretional bending stresses [Buck et al., 1998]. This model is compatible with rapid lithospheric thickening near the axis [Buck, 2001]. Detailed gravity studies, constrained by seismic tomography [Dunn et al., 2000], may be useful to investigate the thermal structure beneath the axis and near-axis ridge flanks, and to test and constrain models for the formation of the axial high.

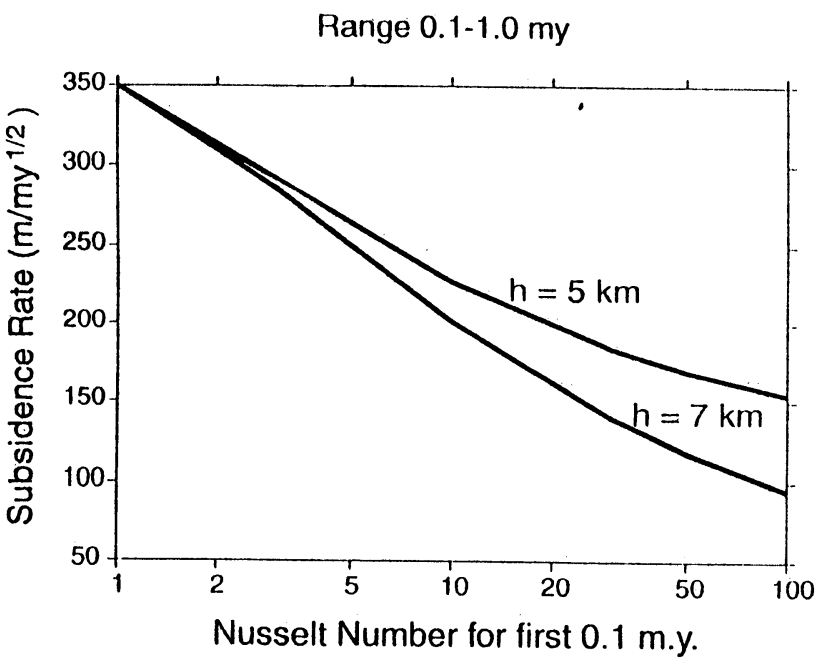

Figure 19. Subsidence rates for the time interval from 0.1 to 1.0 m.y. for the model of Figure $16 \mathrm{~b}$ as a function of Nusselt number for two different thicknesses of the region of enhanced conductivity. The horizontal axis gives the value of the Nusselt number set from the surface to depth $h$ for the first $0.1 \mathrm{~m}$.y. After that time, the Nusselt number is everywhere set to 1 . Subsidence rates for the period from 0.1 to 1.0 m.y. were determined by the same least squares method used in analyzing the observed profiles across ridge axes (Figures 2, 7-11, and 14). The model matches observed subsidence rates for $N u$ in the range of $\sim 15-30$. 


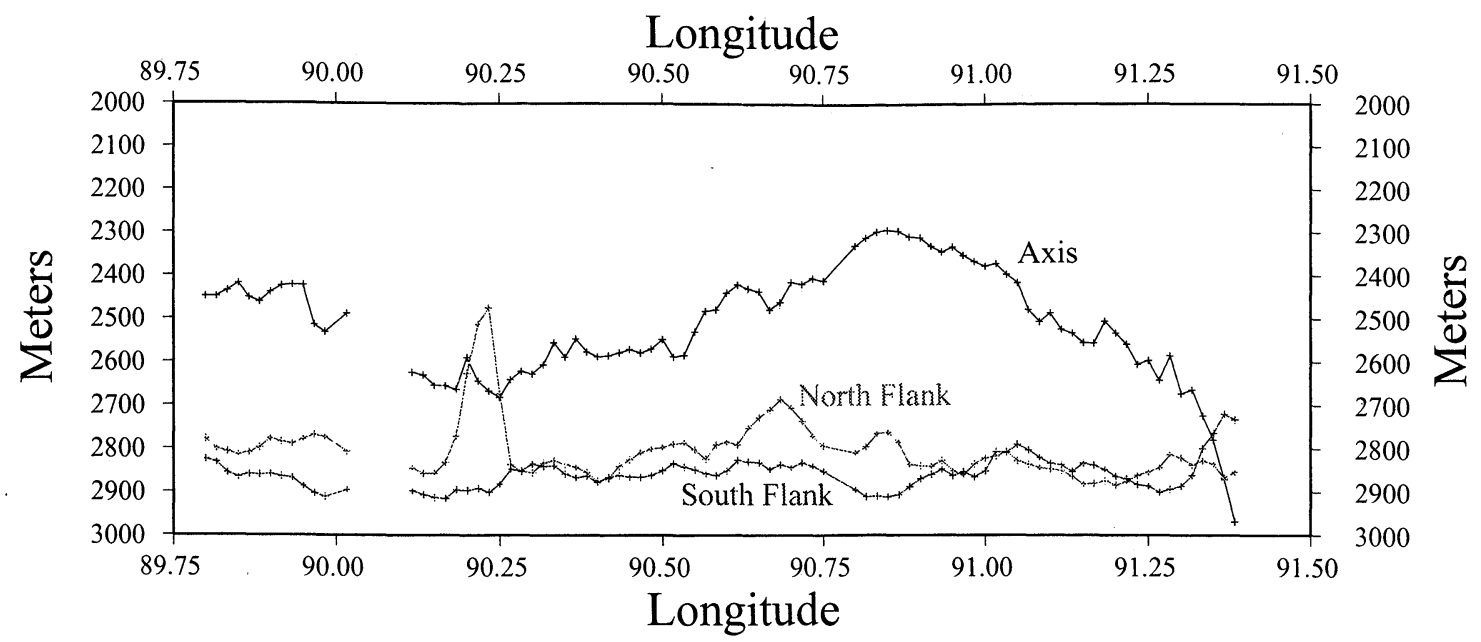

Figure 20. Along-axis and axis-parallel depth profiles from Segment M3 on the SEIR (Figure 6a). Depths were extracted from gridded bathymetric data at $1^{\prime}(1.83 \mathrm{~km})$ intervals along the axis and at $30 \mathrm{~km}$ to the north and to the south of the axis along flow lines. The $x$ axis gives the longitude at which the flow lines cross the axis. Note that the several hundred meter variation in axial depth is not present in the off-axis profiles.

\section{Summary and Conclusions}

1. Near-axis ridge flank subsidence rates observed at intermediate and fast spreading mid-ocean ridges are significantly lower than the rates determined from worldwide data compilations [e.g., Parsons and Sclater, 1977] and the rates observed on older lithosphere at the same segments [Cochran, 1986]. We analyzed bathymetry profiles from well-surveyed segments of the intermediate spreading ( $72-76 \mathrm{~mm} / \mathrm{yr})$ SEIR, fast spreading (91$96 \mathrm{~mm} / \mathrm{yr}$ ) northern EPR, and extremely fast spreading (144 $\mathrm{mm} / \mathrm{yr}$ ) southern EPR. At all three ridges the average ridge flank subsidence rate for crust less than about $1 \mathrm{~m} . \mathrm{y}$. old is less than $200 \mathrm{~m} / \mathrm{m} . \mathrm{y} .^{1 / 2}$.

Histograms of the individual estimates from the SEPR and SEIR show a well-developed peak at 170 to $230 \mathrm{~m} / \mathrm{m} . \mathrm{y} .^{1 / 2}$ with a rapid falloff toward higher values (Figures 3 and 12). Only a few profiles gave subsidence rates as great as Parsons' and Sclater's [1977] worldwide average of $350 \mathrm{~m} / \mathrm{m} . \mathrm{y} .{ }^{1 / 2}$. The number of subsidence rate estimates decreases more slowly on the low side, and a significant number of profiles have very low subsidence rates. The west flank of the $11^{\circ} 45^{\prime} \mathrm{N}-14^{\circ} 15^{\prime} \mathrm{N}$ segment on the NEPR has a distribution similar to that observed at the SEPR and SEIR, but with a somewhat higher mean $\left(221 \mathrm{~m} / \mathrm{m} . \mathrm{y} .^{1 / 2}\right.$ ) (Figure $15 \mathrm{~b})$. The east flank of this segment is nearly flat. The mean and median subsidence rates determined from 21 profiles on the east flank of the segment are both just under $50 \mathrm{~m} / \mathrm{m} . \mathrm{y}^{1 / 2}$.

2. The low subsidence rates observed near the axis on the flanks of intermediate and fast spreading mid-ocean ridges may be the result of vigorous hydrothermal circulation at the ridge axis. The two basic assumptions necessary for this mechanism are (1) that vigorous hydrothermal circulation near the ridge axis extracts a large amount of heat from the crust, resulting in a significantly reduced geothermal gradient within the cooled region, and (2) that the intense hydrothermal circulation is confined to the immediate vicinity $(<5 \mathrm{~km})$ of the axis. Off axis, the extremely vigorous hydrothermal circulation ceases, perhaps due to absence of the shallow heat source provided by the presence of magma at the axis. Conductive heat flow then becomes a primary mechanism of vertical heat transport on the ridge flanks. The very low geothermal gradient within the cooled portion of the uppermost lithosphere retards conductive cooling, and the cooled area needs to be heated from below before a geothermal gradient can be established which permits significant heat to be conducted out of the lithosphere. As a result, subsidence in very young ( $\sim 0.1-1 \mathrm{Ma})$ lithosphere is suppressed

A simple one-dimensional model was used to investigate how a sudden change from very efficient (intense convective) to less efficient (conductive and diffuse convective) heat transport might affect off-axis lithospheric temperatures and subsidence. A Nusselt number parameterization was used to estimate the effect of hydrothermal circulation. In this model a layer of thickness $h$ is initially taken to have a diffusivity that is $N u$ times the normal value of $1 \times 10^{-6} \mathrm{~m}^{2} / \mathrm{s}$. This layer and the half-space that it overlies are initially at a temperature of $1300^{\circ} \mathrm{C}$ and the surface is maintained at $0^{\circ} \mathrm{C}$. After $0.1 \mathrm{~m}$.y. of cooling (about $3.5 \mathrm{~km}$ from the spreading axis for the SEIR or about $7 \mathrm{~km}$ from the axis for the SEPR), the enhanced conductivity is switched off (i.e., the Nusselt number of the top layer is set to 1 so that normal conduction is simulated). We used an explicit finite difference method to solve for the temporal changes in temperature with depth. This model produces subsidence rates in the range which we observe for $N u$ in the range of 15-30 (Figure 19). The isotherms resulting from our model (Figure 16b) are very similar to the thermal structure deduced by Dunn et al. [2000] from a seismic tomography experiment at $9^{\circ} 30^{\prime} \mathrm{N}$ on the EPR.

The isotherms in Figure 16b, as well as those determined by Dunn et al. [2000], are incompatible with current models for the formation of bathymetric axial highs at fast and intermediate spreading ridges. Both the buoyant loading from below model [Madsen et al., 1984; Wang and Cochran, 1993; Magde et al., 1995] and the extensional bending moment model [Eberle and Forsyth, 1998] require a thin lithosphere which does not thicken rapidly away from the axis. A new model for the formation of the axial high based on accretional bending stresses appears to be compatible with this thermal structure [Buck, 2001]. Detailed gravity modeling is needed to further investigate the near-axis thermal structure and the origin of the axial high.

Acknowledgments. We acknowledge informative discussions with Bill Menke and thank Barry Parsons, Jason Phipps Morgan, and Anne Briais for thorough reviews and thoughtful criticism. This work was supported by National Science 
Foundation grants OCE-97-29831 (J.R.C.) and OCE-98-19866 (W.R.B.). Lamont-Doherty contribution 6195.

\section{References}

Anderson, R.N., and M.A. Hobart, The relation between heat flow, sediment thickness and age in the eastern Pacific, J. Geophys. Res., 81, 2968-2989, 1976.

Antrim, L., J.C. Sempere, K.C. Macdonald, and F.N. Spiess, Fine scale study of a small overlapping spreading center at $12^{\circ} 54 \mathrm{~N}$ on the East Pacific Rise, Mar. Geophys. Res., 9, 115-130, 1988.

Bischoff, J.L., Geothermal system at $21^{\circ} \mathrm{N}$, East Pacific Rise: Physical limits on geothermal fluid and role of adiabatic expansion, Science, 207, 1465-1469, 1980.

Bodine, J.H., M.S. Steckler, and A.B. Watts, Observations of flexure and the rheology of the oceanic lithosphere, J. Geophys. Res., 86, 36953707, 1981.

Buck, W.R., Accretional curvature of lithosphere at magmatic spreading centers and the flexural support of axial highs, J. Geophys. Res., 106, 3953-3960, 2001.

Buck, W.R., A. Shah, and A.N. Poliakov, Thermal stresses as a cause of axial highs at mid-ocean ridges (abstract), Eos Trans. AGU, 79 (45), Fall Meet. Suppl., F837, 1998.

Cazenave, A., B. Lago, and K. Dominh, Thermal parameters of the oceanic lithosphere estimated from geoid height data, J. Geophys. Res., 88, 1105-1118, 1983.

Chen, Y.J., and W.J. Morgan, A nonlinear rheology model for mid-ocean ridge axis topography, J. Geophys. Res., 95, 17,583-17,604, 1990.

Chen, Y.J., and J. Phipps Morgan, The effects of spreading rate, the magma budget, and the geometry of magma emplacement on the axial heat flow at mid-ocean ridges, J. Geophys. Res., 101, 11,475-11,482, 1996.

Cochran, J.R., Variations in subsidence rates along intermediate and fast spreading mid-ocean ridges., Geophys. J. R. Astron. Soc., 87, 421-454, 1986.

Cochran, J.R., J.A. Goff, A. Malinverno, D.J. Fornari, C. Keeley, and X. Wang, Morphology of a "superfast" mid-ocean ridge crest and flanks: The East Pacific Rise, $7^{\circ}-9^{\circ} \mathrm{S}$, Mar. Geophys. Res., 15, 65-75, 1993.

Cochran, J.R., J.C. Sempere, and SEIR-Scientific-Team, The Southeast Indian Ridge between $88^{\circ} \mathrm{E}$ and $120^{\circ} \mathrm{E}$ : Gravity anomalies and crustal accretion at intermediate spreading rates, J. Geophys. Res., 102, $15,463-15,487,1997$ a.

Cochran, J.R., B.P. West, C. Small, and D.M. Christie, Morphology and tectonics of propagating rifts on the Southeast Indian Ridge $\left(88^{\circ} \mathrm{E}-\right.$ $131^{\circ}$ E) (abstract), Eos Trans. $A G U, 78$ (46), Fall Meet. Suppl., F674, 1997b.

Cochran, J.R., B.P. West, B. Sylvander, and D.M. Christie, Rift propagation on the Southeast Indian Ridge (abstract), Ann. Geophys, , 16, 292, 1998.

Davis, E.E., and C.R.B. Lister, Fundamentals of ridge crest topography, Earth Planet. Sci. Lett., 21, 405-413, 1974.

Davis, E.E., D.S. Chapman, and C.B. Forster, Observations concerning the vigor of hydrothermal circulation in young crust, J. Geophys. Res., 101, 2927-2942, 1996.

DeMets, C., R.G. Gordon, D.F. Argus, and S. Stein, Current plate motions, Geophys. J. Int., 101, 425-478, 1990.

Detrick, R.S., P. Buhl, E.E. Vera, J.C. Mutter, J.A. Orcutt, J.A. Madsen, and T.M. Brocher, Multichannel seismic imaging of the axial magma chamber along the East Pacific Rise between $9^{\circ} \mathrm{N}$ and $13^{\circ} \mathrm{N}$, Nature, 326, 35-41, 1987.

Doin, M.P., and L. Fleitout, Thermal evolution of the oceanic lithosphere: An alternative view, Earth Planet. Sci. Lett., 142, 121-136, 1996.

Dunn, R.A., D.R. Toomey, and S.C. Solomon, Three-dimensional seismic structure and physical properties of the crust and shallow mantle beneath the East Pacific Rise at $9^{\circ} 30^{\prime} \mathrm{N}, J$. Geophys. Res., 105, 23,537$23,555,2000$

Eberle, M.A., and D.W. Forsyth, An alternative dynamic model of the axial high at fast-spreading ridges, $J$. Geophys. Res., 103, 12,30912,320, 1998.

Edmond, J.M., C. Measures, R.E. McDuff, L.H. Chan, R. Collier, B. Grant, L.I. Gordon, and J.B. Corliss, Ridge crest hydrothermal activity and the balances of the major and minor elements in the oceans, Earth Planet. Sci. Lett., 46, 1-18, 1979.

Gillis, K.M., and P.T. Robinson, Patterns and processes of alteration in the lavas and dykes of the Troodos ophiolite, Cyprus, J. Geophys. Res., 95, 21,523-21,548, 1990.
Goff, J.A., D.J. Fornari, J.R. Cochran, C. Keeley, and A. Malinverno, The Wilkes transform system and "nannoplate", Geology, 21, 623-626, 1993.

Grassle, J.F., The ecology of deep-sea hydrothermal vent communities, Adv. Mar. Biol., 23, 301-362, 1986.

Gregory, R.T., and H.P. Taylor, Jr., An oxygen isotope profile in a section of Cretaceous oceanic crust, Samail ophiolite, Oman: Evidence for $\delta^{18} \mathrm{O}$ buffering of the oceans by deep $(>5 \mathrm{~km})$ seawater-hydrothermal circulation at mid-ocean ridges, J. Geophys. Res., 86, 2737$2755,1981$.

Hart, S.R., and H. Staudigal, The control of alkalies and uranium in seawater by ocean crust alteration, Earth Planet. Sci. Lett., 58, 202-212, 1982.

Hayes, D.E., and K.A. Kane, Long-lived mid-ocean ridge segmentation of the Pacific-Antarctic Ridge and the Southeast Indian Ridge, $J$. Geophys. Res., 99, 19,679-19,692, 1994.

Heestand, R.L., and S.T. Crough, The effect of hot spots on the oceanic age-depth relation, J. Geophys. Res., 86, 6107-6114, 1981.

Henstock, T.J., A.W. Woods, and R.S. White, The accretion of oceanic crust by episodic sill intrusion, J. Geophys. Res., 98, 4131-4161, 1993.

Johnson, H.P., and R.L. Carlson, Variation of sea floor depth with age: A test of models based on drilling results, Geophys. Res. Lett., 19, 19711974, 1992.

Kuo, B.Y., D. Forsyth, and E.M. Parmentier, Flexure and thickening of the lithosphere at the East Pacific Rise, Geophys. Res. Lett., 13, 681$684,1986$.

Langseth, M.G., X. LePichon, and M. Ewing, Crustal structure of the mid-ocean ridges, 5, Heat flow through the Atlantic Ocean floor and convection currents, J. Geophys. Res., 71, 5321-5355, 1966.

Lilley, M.D., R.A. Feely, and J.H. Trefry, Chemical and biochemical transformations in hydrothermal plumes, in Seafloor Hydrothermal Systems Physical, Chemical Biological, and Geological Interactions, Geophys. Monogr. Ser., vol 91, edited by S.E. Humphris et al., pp. 369-391, AGU, Washington, D.C., 1995.

Lin, J., and E.M. Parmentier, Mechanisms of lithospheric extension at mid-ocean ridges, Geophys. J. R. Astron. Soc., 96, 1-22, 1989.

Lister, C.R.B., On the thermal balance of a mid-ocean ridge, Geophys. $J$. R. Astron. Soc., 26, 515-535, 1972.

Lowell, R.P., and L.N. Germanovich, Dike injection and the formation of megaplumes at ocean ridges, Science, 267, 1804-1807, 1995.

Lutz, R.A., and M.J. Kennish, Ecology of deep-sea hydrothermal vent communities: A review, Rev. Geophys., 31, 211-242, 1993.

Lutz, R.A., T.M. Shank, D.J. Fornari, R.M. Haymon, M.D. Lilley, K.V. Von Damm, and D. Desbruyeres, Rapid growth at deep-sea vents, Nature, 371, 663-664, 1994.

Ma, Y., and J.R. Cochran, Bathymetric roughness of the Southeast Indian Ridge: Implications for crustal accretion at intermediate spreading rate mid-ocean ridges, J. Geophys. Res., 102, 17,697-17,711, 1997.

Macdonald, K.C., R. Haymon, and A. Shor, A $220 \mathrm{~km}^{2}$ recently erupted lava field on the the East Pacific Rise near lat $8^{\circ} \mathrm{S}$, Geology, 17, 212$216,1989$.

Macdonald, K.C. et al., The East Pacific Rise and its flanks, $8-18^{\circ} \mathrm{N}$ : History of segmentation, propagation and spreading direction based on SeaMARC II and SeaBeam studies, Mar. Geophys. Res., 14, $299-$ 344, 1992.

Madsen, J.A., D.W. Forsyth, and R.S. Detrick, A new isostatic model for the East Pacific Rise crest, J. Geophys. Res., 89, 9997-10,016, 1984.

Magde, L.S., R.S. Detrick, G.M. Kent, A.J. Harding, J.A. Orcutt, J.C. Mutter, and P. Buhl, Crustal and upper mantle contribution to the axial gravity anomaly at the southern East Pacific Rise, J. Geophys. Res., 100, 3747-3766, 1995.

McKenzie, D.P., Some remarks on heat flow and gravity anomalies, $J$. Geophys. Res., 72, 6261-6273, 1967.

McNutt, M.K., and K.M. Fischer, The South Pacific Superswell, in Seamounts, Island,s and Atolls, Geophys. Monogr. Ser., vol 43, edited by B. H. Keating, P. Fryer, R. Batiza, and G.W. Boehlert, pp. 25-34, AGU, Washington, D.C., 1987.

Morton, J.L., and N.H. Sleep, A mid-ocean ridge thermal model: Constraints on the volume of axial hydrothermal flux, J. Geophys. Res., $90,11,345-11,353,1985$.

Morton, J.L., N.H. Sleep, W.R. Normark, and D.H. Tompkins, Structure of the southern Juan de Fuca Ridge from seismic reflection records, $J$. Geophys. Res., 92, 11,315-11,326, 1987.

Mutter, J.C., S.M. Carbotte, W. Su, L. Xu, P. Buhl, R.S. Detrick, G.A. Kent, J.A. Orcutt, and A.J. Harding, Seismic images of active magma systems beneath the East Pacific Rise between $17^{\circ} 05^{\prime}$ and $17^{\circ} 35^{\prime} \mathrm{S}$, Science, 268, 391-395, 1995. 
Nehlig, P., and T. Juteau, Flow porosities, permeabilities and preliminary data on fluid inclusions and fossil thermal gradients in the crustal sequence of the Sumail ophiolite (Oman), Tectonophys., 151, 188$221,1988$.

Parker, R.L., and D.W. Oldenburg, Thermal model of ocean ridges, Nature Phys. Sci., 242, 137-139, 1973.

Parsons, B., and D.P. McKenzie, Mantle Convection and the thermal structure of plates, J: Geophys. Res., 83, 4485-4496, 1978.

Parsons, B., and J.G. Sclater, Ocean floor bathymetry and heat flow, $J$. Geophys. Res., 82, 803-827, 1977.

Phipps Morgan, J., and Y.J. Chen, The genesis of oceanic crust: magma injection, hydrothermal circulation and crustal flow, J. Geophys. Res., 98, 6283-6297, 1993.

Phipps Morgan, J., E.M. Parmentier, and J. Lin, Mechanisms for the origin of mid-ocean ridge axial topography: Implications for the thermal and mechanical structure of accreting plate boundaries, J. Geophys. Res., 92, 12,823-12,836, 1987.

Rona, P.A., TAG hydrothermal field: Mid-Atlantic Ridge Crest at latitude $26^{\circ}$ N, J. Geol. Soc. London, 137, 385-402, 1980.

Rona, P.A., Hydrothermal mineralization at oceanic ridges, Can. Mineral., 26, 431-465, 1988.

Rona, P.A., G. Klinkhammer, T.A. Nelsen, J.H. Trefry, and H. Elderfield, Black smokers, massive sulfides and vent biota at the Mid-Atlantic Ridge, Nature, 321, 33-37, 1986.

Sandwell, D., and G. Schubert, Lithospheric flexure at fracture zones, $J$. Geophys. Res., 87, 4657-4667, 1982.

Sclater, J.G., and J. Francheteau, The implications of terrestrial heat flow observations on current tectonic and geochemical models of the crust and upper mantle of the Earth, Geophys. J. R. Astron. Soc., 20, 509$542,1970$.

Sclater, J.G., R.N. Anderson, and M.L. Bell, The elevation of ridges and the evolution of the central eastern Pacific, J. Geophys. Res., 76, 7888-7915, 1971 .

Sclater, J.G., R.P. Von Herzen, D.L. Williams, and R.N. Anderson, The heat flow low on the flank of the Galapagos spreading center, Geophys. J. R. Astron. Soc., 38, 609-626, 1974.

Sempere, J.C., J.R. Cochran, and SEIR-Scientific-Team, The Southeast Indian Ridge between $88^{\circ} \mathrm{E}$ and $120^{\circ} \mathrm{E}$ : Variations in crustal accretion at constant spreading rate, J. Geophys. Res, 102, 15,489-15,505, 1997.

Seyfried, W.E., Experimental and theoretical constraints on hydrothermal alteration processes at mid-ocean ridges, Annu. Rev. Earth Planet. Sci., 15, 317-335, 1987.

Sleep, N.H., Sensitivity of heat flow and gravity to the mechanism of seafloor spreading, J. Geophys. Res., 74, 542-549, 1969.

Sleep, N.H., Hydrothermal convection at ridge axes, in Hydrothermal Processes at Seafloor Spreading Centers, edited by P.A. Rona et al., pp. 71-82, Plenum, New York; 1983.

Sleep, N.H., Hydrothermal circulation, anhydrite precipitation, and thermal structure at ridge axes, J. Geophys. Res., 96, 2375-2387, 1991.

Sohn, R.A., S.C. Webb, J.A. Hildebrand, and B.D. Cornuelle, Threedimensional tomographic velocity structure of upper crust, coaxial segment, Juan de Fuca Ridge: Implications for on-axis evolution and hydrothermal circulation, J. Geophys. Res., 102, 17,679-17,695, 1997.

Stein, C.A., and S. Stein, A model for the global variation in oceanic depth and heat flow with lithospheric age, Nature, 359, 123-129, 1992.

Stein, C.A., and S. Stein, Constraints on hydrothermal heat flux through the oceanic lithosphere from global heat flow data, J. Geophys. Res. 99, 3081-3095, 1994.

Stein, C.A., S. Stein, and A.M. Pelayo, Heat flow and hydrothermal circulation, in Seafloor Hydrothermal Systems Physical, Chemical Biological, and Geological Interactions, Geophys. Monogr. Ser., vol 91, edited by S.E. Humphris et al., pp. 425-445, AGU, Washington, D.C., 1995.

Talwani, M., C.C. Windisch, and M.G. Langseth, Reykjanes Ridge Crest A detailed geophysical study, J. Geophys. Res., 76, 473-517, 1971.

Tapponnier, P., and J. Francheteau, Necking of the lithosphere and the mechanics of slowly accreting plate boundaries, J. Geophys. Res., 83, 3955-3970, 1978.

Turcotte, D.W., and G. Schubert, Application of Continuum Physics to Geological Problems, 449 pp., John Wiley, New York, 1982.

Von Damm, K.L., Seafloor hydrothermal activity: Black smoker chemistry and chimneys, Annu. Rev. Earth Planet Sci., 18, 173-204, 1990.

Von Damm, K.L., Controls on the chemistry and temporal variability of seafloor hydrothermal fluids, in Seafloor Hydrothermal Systems Physical, Chemical Biological, and Geological Interactions,, Geophys. Monogr. Ser., vol 91, edited by S.E. Humphris et al. pp. 222-247, AGU, Washington, D.C., 1995.

Wang, X., and J.R. Cochran, Gravity anomalies, isostasy and mantle flow at the East Pacific Rise crest, J. Geophys. Res., 98, 19,505-19,531, 1993.

Watts, A.B., An analysis of isostasy in the world's oceans, 1. HawaiianEmperor Seamount Chain, J. Geophys. Res., 83, 5989-6004, 1978.

Williams, D.L., T.M. Narasimhan, R.N. Anderson, M.D. Zoback, and K. Becker, Convection in the oceanic crust: Simulation of observations from Deep Sea Drilling Project hole 504B, Costa Rica Rift, J. Geophys. Res., 91, 4877-4889, 1986.

Wilson, D.S., Focused upwelling beneath mid-ocean ridges: Evidence from seamount formation and isostatic compensation of topography, Earth. Planet. Sci. Lett., 113, 41-55, 1992.

Wolery, T.J., and N.H. Sleep, Hydrothermal circulation and geochemical flux at mid-ocean ridges, J. Geol., 84, 249-275, 1976.

W.R. Buck and J.R. Cochran, Lamont-Doherty Earth Observatory of Columbia University, 109 Oceanography Building, Palisades, NY 10964, USA. (jrc@ldeo.columbia.edu)

(Received July 11, 2000, revised February 2, 2001; accepted March 25, 2001.) 